\title{
Assessing the Adequacy of Models for Risk-Informed Decisions (P-109)
}

March 2016

\section{United States}

Nuclear Regulatory Commission

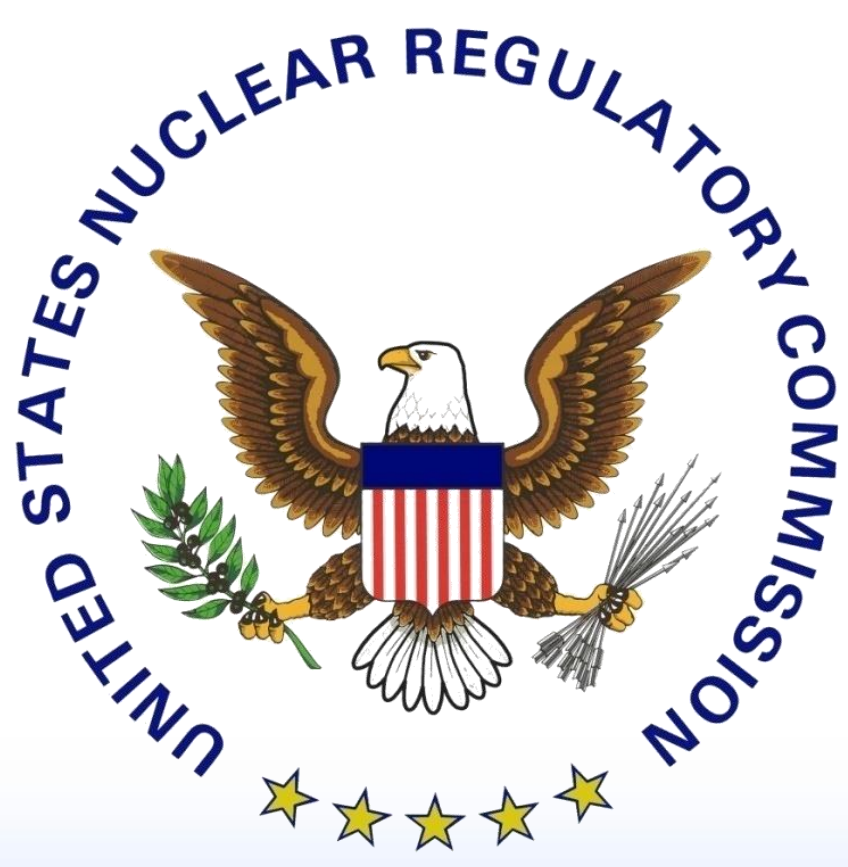




\section{DISCLAIMER NOTICE}

This report was prepared as an account of work sponsored by an agency of the United States Government. Neither the United States Government nor any agency thereof, or any of their employees, makes any warranty, expressed or implied, or assumes any legal liability of responsibility for any third party's use, or the results of such use, or any information, apparatus, product or process disclosed in this report, or represents that its use by such third party would not infringe privately owned rights. 


\section{Assessing the Adequacy of Models for Risk-Informed Decisions}

March 2016

Curtis Smith - Curtis.Smith@inl.gov Bob Youngblood - Robert.Youngblood@inl.gov 


\section{Outline}

- Overview of some ways to go wrong in making decisions

- Common deficiencies in reasoning and in modeling

- Thinking clearly about uncertainty

- Case Studies

- Concluding Thoughts 


\section{Outline}

- Overview of some ways to go wrong in making decisions

- Common deficiencies in reasoning and in modeling

- Thinking clearly about uncertainty

- Case Studies:

1: NASA Challenger

2: Davis-Besse vessel-head event

Interlude: Critical Thinking

3: NASA Columbia

4: Fukushima

- Concluding Thoughts

For each:

- Recap the history

- Discuss what went wrong (or right), and possible reasons why 


\section{The Hidden Traps in Decision Making}

(Hammond, Keeney, Raiffa in Harvard Business Review)

- Anchoring: Giving disproportionate weight to the first information you receive

- Status quo: Favoring alternatives that perpetuate the existing situation

- Sunk costs: Making choices in a way that justifies past, flawed choices

- Confirming evidence: Seeking information that supports your existing point of view

- Estimating and forecasting: Being overly influenced by vivid memories when estimating 


\section{Some Causes of DM Failures}

- Pressure to get the "right" answer

- Rush to judgment

- Schedule/cost pressure

- Competing priorities

- Safety vs. economics

- Missing a milestone may affect others

- Convenient explanations

- New characteristics/issues attributed to existing or known causes

- Failure to perceive a problem once it has occurred

- Groupthink

- Malice
- Correctly answering the wrong question

- Overgeneralization

- Illogical reasoning

- Flawed thought process

- Incorrect consideration of causal mechanisms

- Lack of information distribution

- Analysis insights and recommendations do not get distributed or are ignored

- Failure to anticipate a problem

- Failure to attempt to solve it after it has been perceived

- Simple errors

Can you think of any other causes?? 


\section{Modeling Errors in General}

- Poor formulation of Inputs to Bayes' Theorem

- Incompleteness: Insufficient space of competing hypotheses

- Prior

- Likelihood model

- Poor [simulation] model

- Normalization of Deviance 


\section{Bayes' Theorem:}

- Bayes' "theorem" states that

$$
\begin{aligned}
& p\left(H_{i} \mid E\right)=P\left(H_{i}\right) \frac{p\left(E \mid H_{i}\right)}{p(E)}, \\
& p(E)=p\left(E \mid H_{i}\right) p\left(H_{i}\right)
\end{aligned}
$$

- where

- $H_{i}$ represents a hypothesis whose probability is to be updated with new evidence,

- $p\left(H_{i}\right)$ is the prior probability of $H_{i}$,

- E represents a new piece of evidence,

$-p(x / y)$ is the conditional probability of $x$ given $y$,

$-p(E)$, the prior probability of the observed evidence 


\section{Application of Bayes' Theorem: Gorillas in the room}

- Structure of the hypothesis space: what ARE the $\{H\}$ ?

- As in the "ESP example" (later slides)

- Other examples abound

- Selection (formulation) of the prior $p(H)$

- In this class, limited time for discussion

- Other NRC classes (e.g., P-102, P-502) consider this topic in more detail

- Modeling of the likelihood $p\left(E / H_{i}\right)$

- If you're comparing a model to data, then this includes all sorts of things, not least model form uncertainty 


\section{Really only one gorilla}

- Bayes' "theorem" states that

$$
\begin{aligned}
& p\left(H_{i} \mid E\right)=P\left(H_{i}\right) \frac{p\left(E \mid H_{i}\right)}{p(E)}, \\
& p(E)={ }_{i} p\left(E \mid H_{i}\right) p\left(H_{i}\right)
\end{aligned}
$$

- Everything on the right-hand side includes modeling choices made by the user

- So the "theorem" is an identity, but you can still go very wrong

- We have met the enemy, and he is us 


\section{Completeness (of hypothesis space) (Probability Theory: The Logic of Science, E. T. Jaynes)}

- Consider an experiment to determine whether an individual has extrasensory perception (ESP)

- Experiment involves seeing whether individual can sense which of several possible cards is held

- It's possible to guess correctly sometimes, but EXTREMELY unlikely to guess correctly a large fraction of the time

- Consider two hypotheses: yes (ESP) and no (no ESP)

- Establish prior probabilities for these two hypotheses

- The data come in. The individual gets everything right. You update your prior with data, and it looks like the individual has ESP.

- What do you conclude? 


\section{Completeness (of hypothesis space)}

(Probability Theory: The Logic of Science, E. T. Jaynes)

- At this point, Jaynes would admit a third hypothesis: deception

- The answer YOU get may not be the answer Jaynes gets

- But his posterior will assign higher probability to "deception" than to ESP 


\section{Real World vs. Models}

- Risk models must be constantly and critically

- Reexamined for consistency with system configuration/ operation

- Updated with relevant information (e.g., accident precursor analysis...)

- To ensure closest correlation and fastest convergence between "real world" and the "risk model"

\section{Real World versus Models}

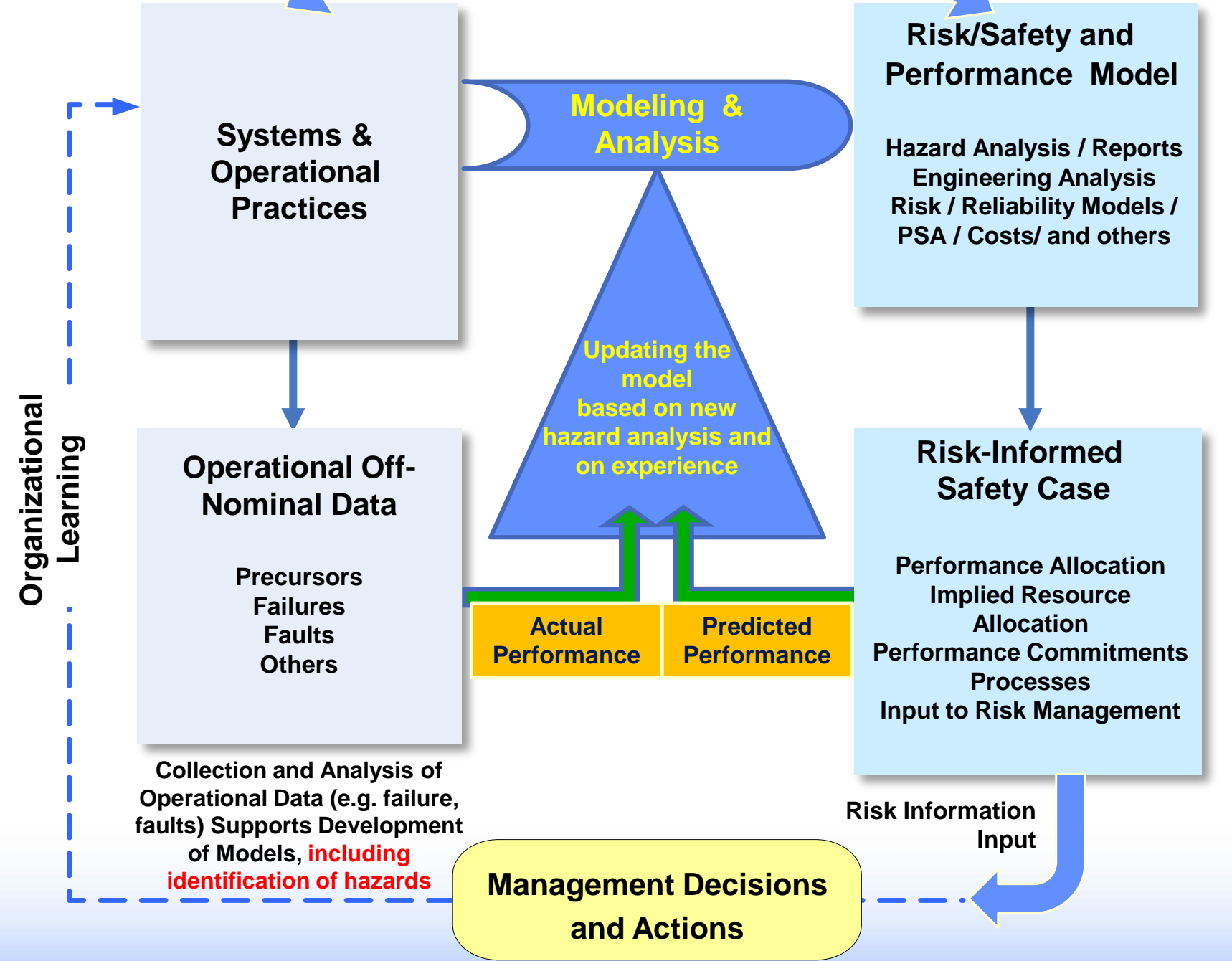




\section{Analysis of precursor events (1 of 3)} (per Bier and Mosleh)

- "According to the particular model considered in this work [Bier and Mosleh], the frequency of a rare event [e.g, an accident] can be represented as

$$
={ }_{i=1} P_{i}
$$

- where

- $\phi=$ frequency of the rare event of interest.

$-\lambda_{i}=$ the frequency of precursor type $i$.

- $P_{i}=$ the conditional probability of the event of interest, given a precursor of type i. ..." 


\section{Analysis of precursor events (2 of 3 )}

(per Bier and Mosleh)

- Your prior state of knowledge: you think that

- $P$ is of order unity, with some uncertainty

- if event i occurs, we will almost surely have an accident.

$-\lambda$ is very small, with uncertainty.

- Event $\mathrm{i}$ isn't going to happen.

- Therefore, $\phi$ is small, with uncertainty.

- Now you observe event i, but it doesn't lead to an accident. What do you conclude? 


\section{Analysis of precursor events (3 of 3 )}

(per Bier and Mosleh)

- Some people are cheered up by observation of $i$, but no accident, because $P$ must be smaller than they thought. So after a few occurrences, they worry less about this class of events.

- This is closely related to "normalization of deviance."

- Bier and Mosleh did the math (Bayesian updating)

- Yes, P goes down from its prior. But $\lambda$ goes UP from its prior, potentially a lot.

- The prior said this would be very rare, but it happened.

- Details may vary, but in examples of this type, the posterior estimate of $\phi$ usually goes up, not down.

- This won't necessarily hold if you also learn other things from the event, such as things that change your phenomenological model 


\section{Objective}

- Our primary objective in this course is to:

Improve the NRC staff's awareness of the factors that contribute to uncertainty in predictive models and the need to identify, characterize and communicate the uncertainties to the risk-informed decision-maker 


\section{Subsidiary objectives}

- Review NRC efforts to predict initiation/progression of passive system degradation phenomena and assess associated risk

- Emphasis on cases where inappropriate extrapolation from known data to unknown situations resulted in poor decisions

- Improve NRC staff understanding of

- Risk assessment

- PRA quality for issues such as passive component degradation

- Reinforce need to evaluate overall adequacy/validation of physical and logical models used to support decision-making

- Clarify expectations regarding communication of adequacy of specific models 


\section{Background}

- Davis-Besse reactor pressure vessel head wastage event

- Boric acid wastage believed to not be a concern

- NRC decision to allow continued operation made with incomplete and faulty information

- Post-event evaluations revealed this to be highly significant issue

- GAO was highly critical

- Leading to LIC-504

among other things

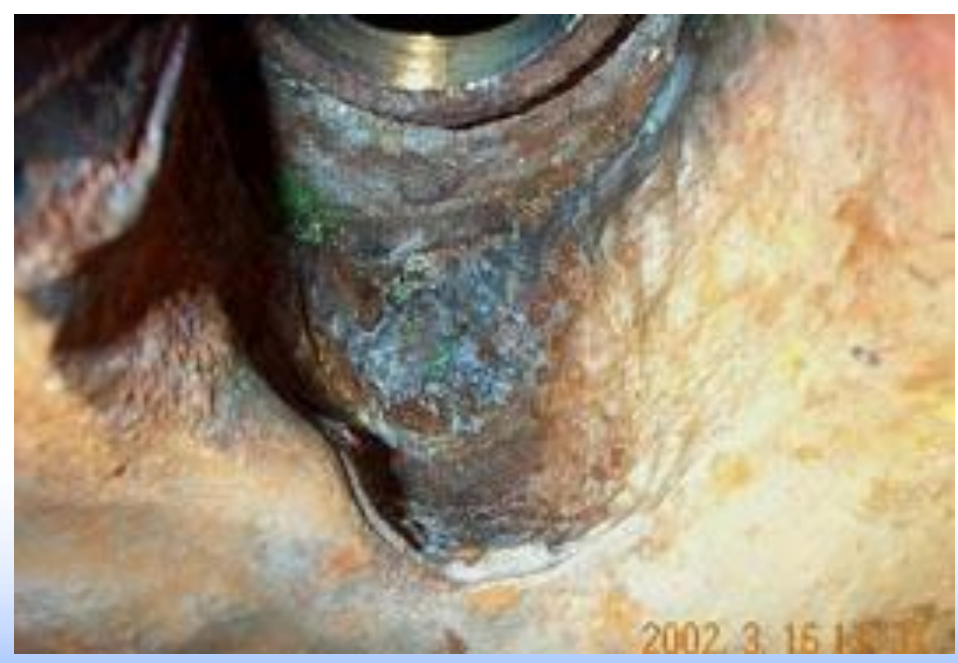




\section{THINKING CLEARLY ABOUT UNCERTAINTY}




\section{Uncertainties in Models Characterized}

- Our "model of the world"

- In the scientific and engineering community, uncertainties generally are separated into two categories

- Random/stochastic

- or "aleatory"

- State of knowledge

- or "epistemic"

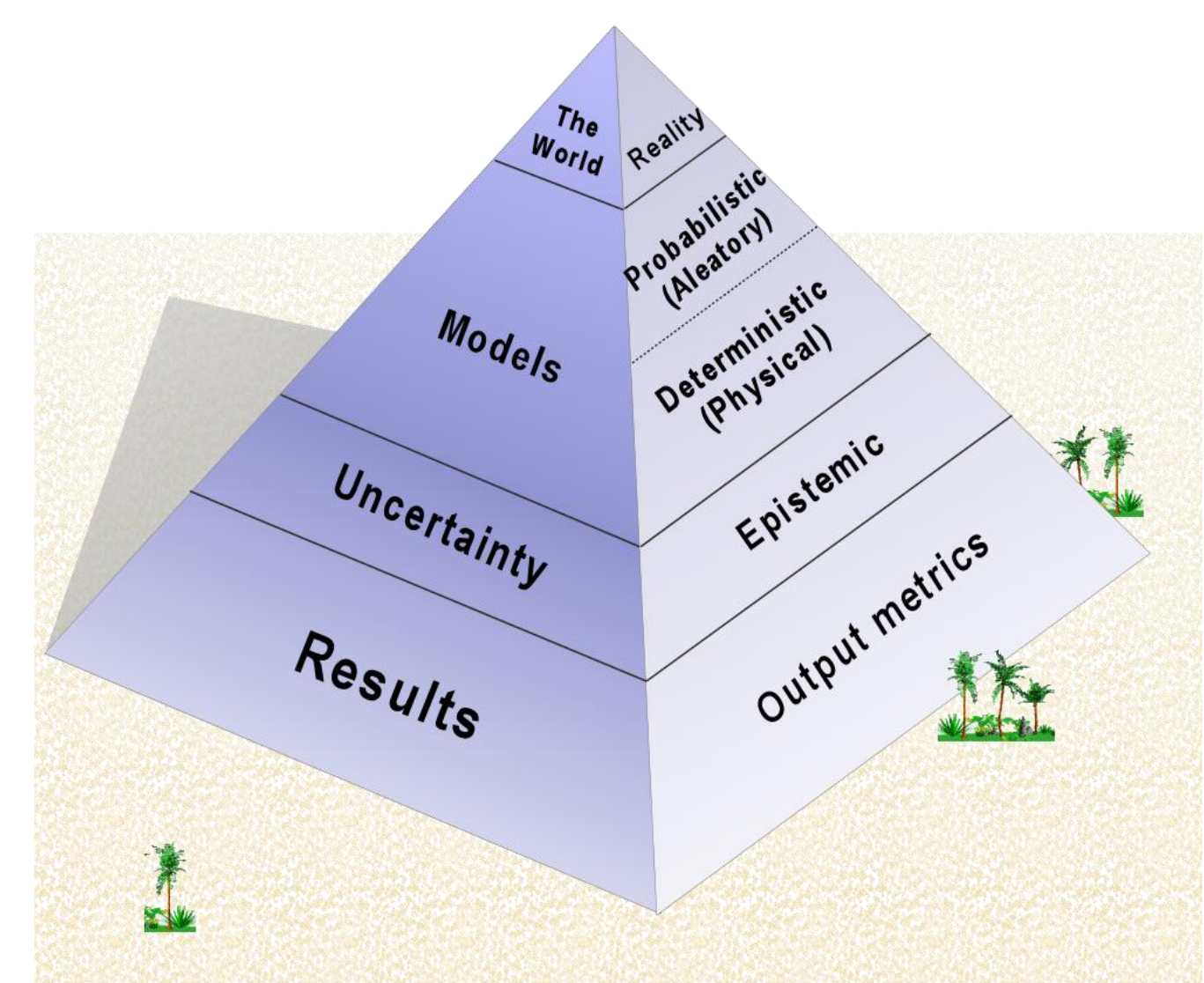




\section{Aleatory}

- Aleatory models represent randomness in the outcome of a process

- For example, flipping a coin is "random" process

- Often modeled by a binomial distribution

- Characterize \# of heads (or tails) seen for given \# of flips

- When flipping a coin, the "random," but observable, quantity is number of heads/tails

- Probabilities are not observable

- We rely on model (such as binomial) to estimate probability for certain outcomes (e.g., two heads out of three coin tosses)

- These are the same models we described as "probabilistic"

Definition of aleatory:

Pertaining to stochastic events, the outcome of which is described by a probability. From the Latin alea (game of chance, die). 


\section{Aleatory}

- In passive system modeling, aleatory uncertainty includes

- All "stochastic" or "random" processes (e.g., vortices in fluid flow, ionizing radiation effects, crack growth)

- Aleatory uncertainty is really a modeling choice

- Represents a complex (some might say irreducible) phenomenon that resists deterministic modeling

- Predicting decay event is the classic example

- Why might a "random" process be too complex for deterministic modeling?

- Very sensitive to initial conditions (chaotic)

- Aleatory model sufficient for decision making

- Too resource intensive to develop deterministic model

- Causal factors not well understood

Operationally, if we engineer systems that are as close to identical as we can make them, and they don't behave identically, there is "aleatory" uncertainty Example: Light bulbs burning out at different instants 


\section{Epistemic}

- Epistemic uncertainty represents how accurate our state of knowledge is about the model, regardless of the model type

- Within this type of uncertainty, we include a laundry list of elements

- Imperfect knowledge of the model parameters (i.e., parametric uncertainty)

- Issues on the model itself (i.e., modeling uncertainty) including

- Simplifications

- Competing models (model form uncertainty)

- Truncation

- Scope

- Completeness

- Errors during quantification

Definition of epistemic:

Pertaining to the degree of knowledge of events. From the Greek episteme (knowledge). 


\section{Epistemic}

- Parametric uncertainty typically does get evaluated

- Model parameter information may have differing degrees of certainty

- Decay constant for our radioactive decay model is typically known very accurately

- However, it is possible that other epistemic uncertainties have a larger impact on overall results

- Model error or uncertainty may be more significant than those associated with other epistemic impacts

- Modeling uncertainty (from NUREG/CR-6311)

"variability in model prediction due to plausible alternative input values (input uncertainty) or to plausible alternative model structures (structural uncertainty)." 


\section{Epistemic}

- In passive system degradation modeling, epistemic uncertainty includes

- The selection and construction of the passive failure model

- Parametric formulation (e.g., use of the KWU-KR or EPRI-ChexalHorowitz FAC model)

- Time discretization and geometry nodalization

- Boundary conditions (e.g., initial states, transition properties)

- Model parameter information

- Flow rates, temperatures, corrosion rate, material properties, exposure time, fluxes, etc.

- Model limitations (especially phenomenological ones)

- In probabilistic fracture mechanics (PFM) epistemic uncertainty includes

- Generalized flaw distributions

- Neutron irradiation embrittlement data bases

- Neutron fluences 


\section{Epistemic $\rightarrow$ precision or accuracy?}

- Imagine that you are a materials scientist at the NRC studying radiation-induced damage of a new shielding material

- The modeling has taken several years

- You publish your results and find they are

- Praised for their precision

- Criticized for their lack of accuracy

- How is this possible?

- Precision is measured with respect to detail

- Accuracy is measured with respect to reality

- In PRA applications, sometimes criticized for over-precision

- Bias leading to underestimating the overall uncertainty

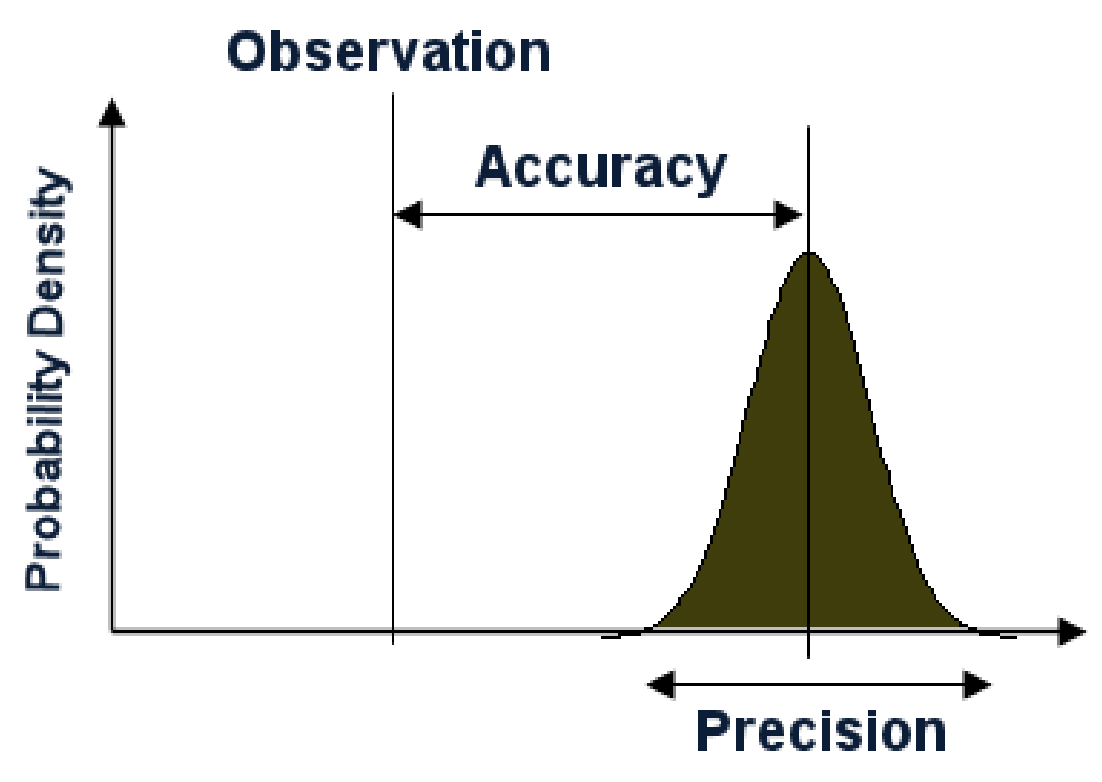

Degradation Model

- We usually can't tell how "accurate" we are 


\section{Integrated Decision Making}

- Uncertainty in deterministic and probabilistic models comes from our imperfect knowledge

- Integrated decision making uses existing regulations, defense in depth, safety margins, risk, and performance monitoring

- Risk models allow explicit treatment of some uncertainty

- These models (both probabilistic and deterministic) cannot be complete

- One reason for the riskinformed approach to regulatory decisionmaking

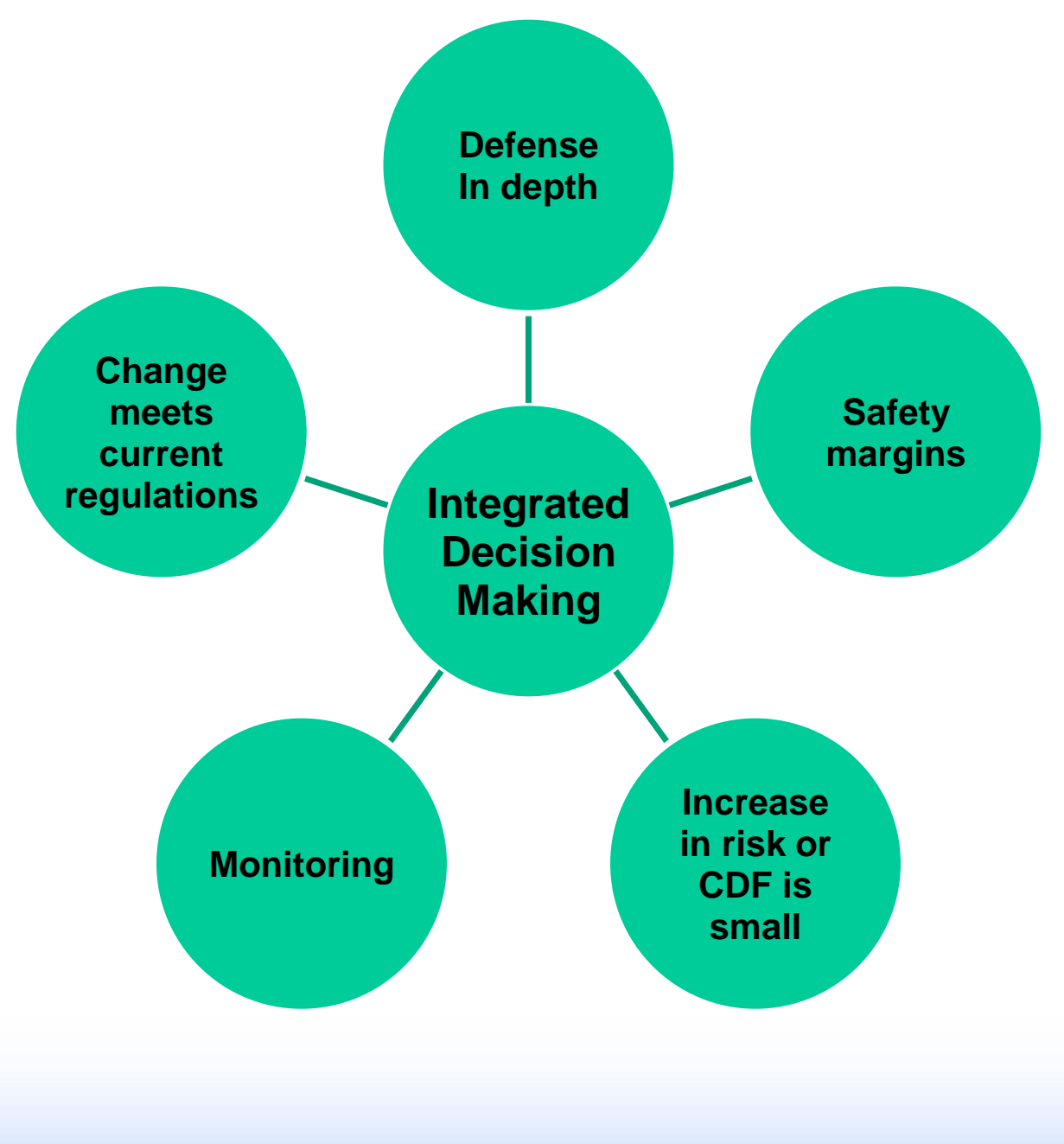




\section{Workshop}

You are asked to develop a model that predicts the probability your car will fail to start tomorrow morning

- Identify the basic structure of your model

- Inputs, assumption, boundary conditions, etc

- What are sources of uncertainty?

- How would you characterize those uncertainties?

- Epistemic vs. aleatory 


\section{Characterize the Uncertainties}

- Uncertainties only make sense in the context of a "frame of reference"

- Every probability is a conditional probability

- The same can be said for deterministic models we use

- The models themselves have pretty rigid "frames of reference:" where, when, how, and why they are applicable

- When used outside these realms, the uncertainty may become large (to the point of ignorance)

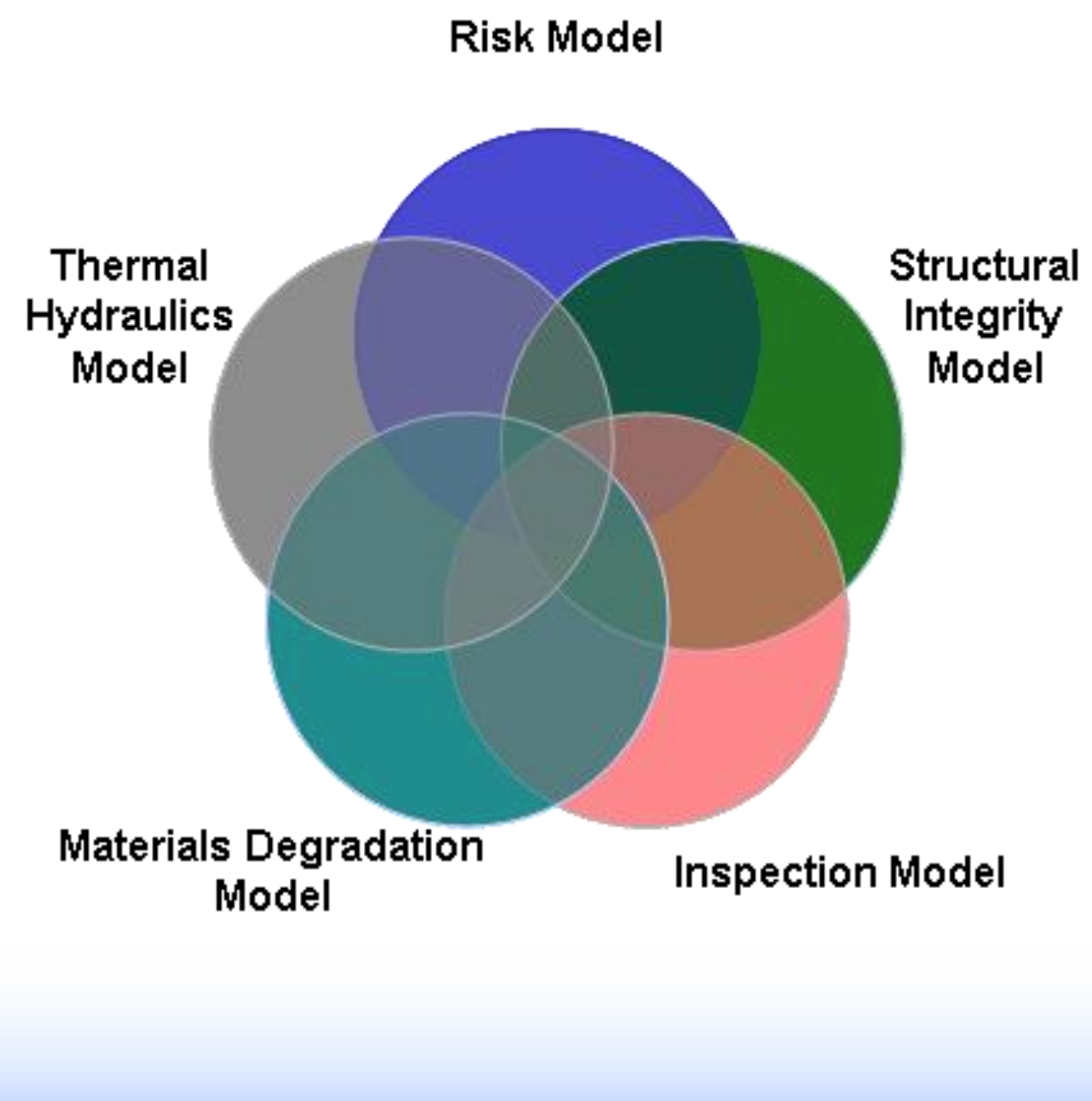




\section{Characterizing the Uncertainties}

- However, several methods are available to characterize analysis uncertainty

- Probabilistic

- Bayesian numerical methods

- Other

- Sensitivity studies

- Graphical methods

- Recall that models have a "frame of reference"

- Key features that will drive uncertainty in any model include

- Simplifying assumptions that are made

- Boundary/initial conditions that are specified

- Range of applicability of the model

Everything should be as simple as possible, but not simpler. ---Widely Attributed to A. Einstein 


\section{Characterizing the Uncertainties}

- Sensitivity analysis is not the same as an uncertainty analysis

- Uncertainty analysis yields a (possibly large) set of plausible outcomes

- These outcomes are tied to their likelihoods via a probability distribution

- Sensitivity analysis determines a relative change in the model output given changes in

- Input parameters

- Model structure

- Sensitivity analysis yields a "localized" what-if analysis

- The likelihood of the input actually taking the value specified is not addressed

- Possible to evaluate conditions that, in practice, may not occur

- Sensitivity analysis can tell you which parts of the model are driving your results

- This is critical information for decision makers 


\section{Characterizing the Uncertainties}

- Reality checks are a key element to model validation, analysis, and decision making

- Different types of checks are used

- Comparing analysis results (predicted outcome) with past or near-term future events

- Common technique in PRA - can be used to see if specific outcomes (e.g., an initiator and a component failure) occur

- Some events, however, are rare - we would not expect to see them even over a long period of time

- Some events we may not have in the PSA (e.g., passive system failures) - do we see these events?

- Comparing like events

- Decision makers frequently have to make preference decisions indifferent options should truly be equal

- Boundary condition checks

- Do "worst case" conditions make sense? 


\section{Characterizing the Uncertainties}

- Reality checks useful for unvalidated models

- Uses available opportunities to check model predictions against observations

- These checks typically involve observable effects that correspond to intermediate calculation results

- Example: for control rod drive circumferential cracks

- Improved models predict the correct total number of circumferential cracks that were found in the seven $B \& W$ reactors

- However, predictive size distribution was optimistic for larger $\left(>60^{\circ}\right.$ ) cracks
- To predict nozzle failure, must predict a frequency of occurrence for cracks twice the size of the largest found

- With the models already underpredicting at $165^{\circ}$

- What is prediction error at $330^{\circ}$ ?

- Models most likely to be nonconservative

- The best predictions (W. Shack at $A N L)$ :

\begin{tabular}{cccc} 
& Observed & \multicolumn{2}{c}{ Predicted } \\
angle & \# found & $\#$ & st \\
dev & & 9 & \\
30 & 7 & 9.0 & 2.0 \\
60 & 4 & 2.8 & 1.1 \\
90 & 3 & 2.4 & 1.0 \\
120 & 2 & 1.7 & 0.8 \\
150 & 2 & 1.3 & 0.6 \\
165 & 2 & 1.1 & 0.5
\end{tabular}




\section{Characterizing the Uncertainties}

- Graphical methods

- A tool for looking for and thinking about trends, outliers, patterns, and other behavior

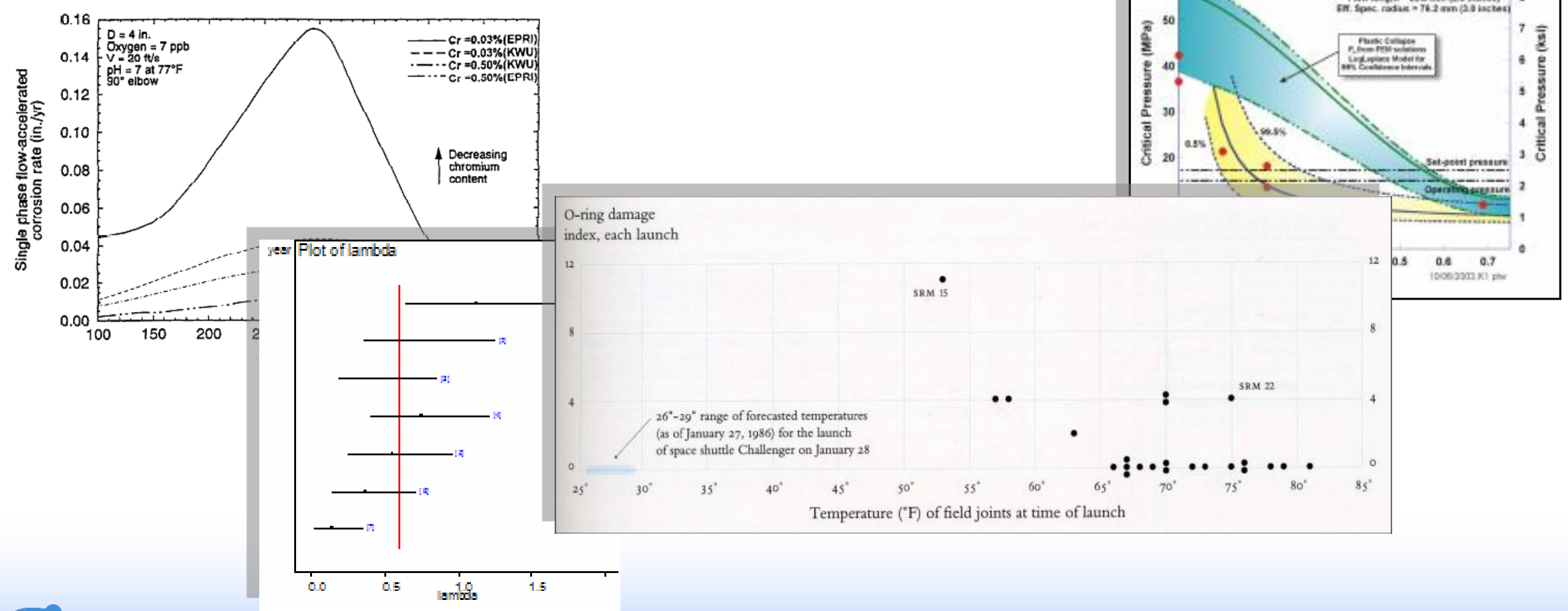




\section{Characterizing the Uncertainties}

- A variety of numerical methods and tools are available to provide quantify uncertainty, for example:

- Analytical

- Monte Carlo sampling (e.g., via tools like SAPHIRE)

- Bayesian probability quantification

- Classical statistical approaches

- These are in addition to the methods and tools specific to materials degradation, structural analysis, and thermal-hydraulics 


\section{Characterizing the Uncertainties}

- Monte Carlo sampling

- Approximates model output by generating a large random sample from the input distributions

- Useful for propagating uncertainties through deterministic physical model

- Fault tree in PRA

- FAC prediction using corrosion model

- Flow rate of a pump via thermal-hydraulics code
- The Monte Carlo sampling process:

- Randomly sample a value of each parameter

- Each sample is used to calculate the quantity represented by the model

- This sampling process is repeated many times

- Use new sampled values of the parameters on each iteration

- Obtain many calculated values of desired result

- Resulting values are a pseudo-random sample from the epistemic model distribution 


\section{Characterizing the Uncertainties}

- However, one needs to critically question numerical methods such as Monte Carlo

- Are the models/distributions applicable?

- Are we seeing convergence in results?
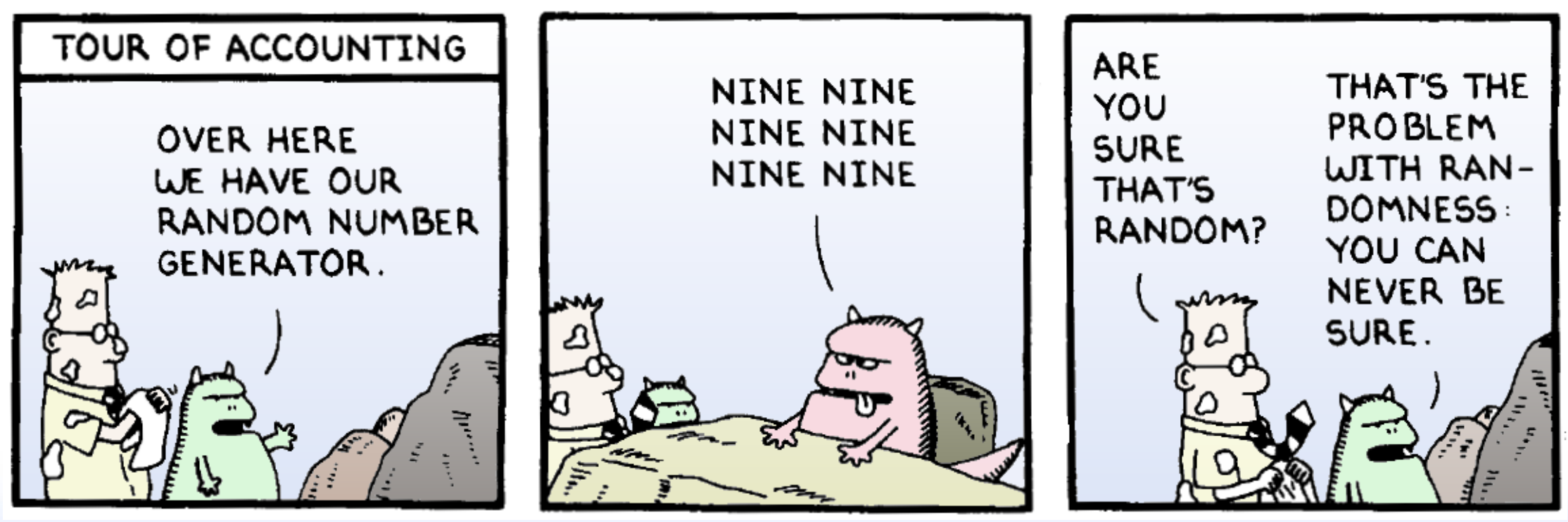

"Dilbert" Scott Adams 


\section{Characterizing the Uncertainties}

- SAPHIRE risk assessment software is NRC-sponsored PRA tool to

- Model a system's response to upset conditions (initiating events)

- Quantify associated outcome frequencies

- For nuclear power plant applications, SAPHIRE can

- Identify important contributors to core damage (Level 1 PRA)

- Analyze containment performance during a severe accident in order to quantify radioactive releases (Level $2 P R A$ )

- Has five built-in common aleatory models

- Poisson and binomial-based

- Has 13 built-in common epistemic distributions

- For example, lognormal, gamma, beta, normal, ...

- Can be extended to allow other aleatory or deterministic models

- For example, the FAC calculations described in NUREG/CR-5632 


\section{Characterizing the Uncertainties}

- Keep in mind that simply having a model does not guarantee certainty

- May be missing a variety of uncertainties such as

- Partial correlation between events

- Modeling issues such as realism, exclusions, and errors

- In the Davis-Besse post analysis, two detailed clad failure models were available

- Initial model appears incorrect for this event

- Averaging the two models also does not provide correct representation

- If a high degree of belief is put on the wrong model (even if it is a complex, computer-based model with uncertainty sampling)

- Decisions made based on that model may not adequately protect the public 


\section{Communicating the Uncertainties}

- To effectively communicate implies that the spectrum of information related to the process being modeled is understood by all

- Need to realize that

- Not all information will be known

- What information is known will be imprecise

- Information content will change over time

- The value placed on different types of information will differ depending on how it is used

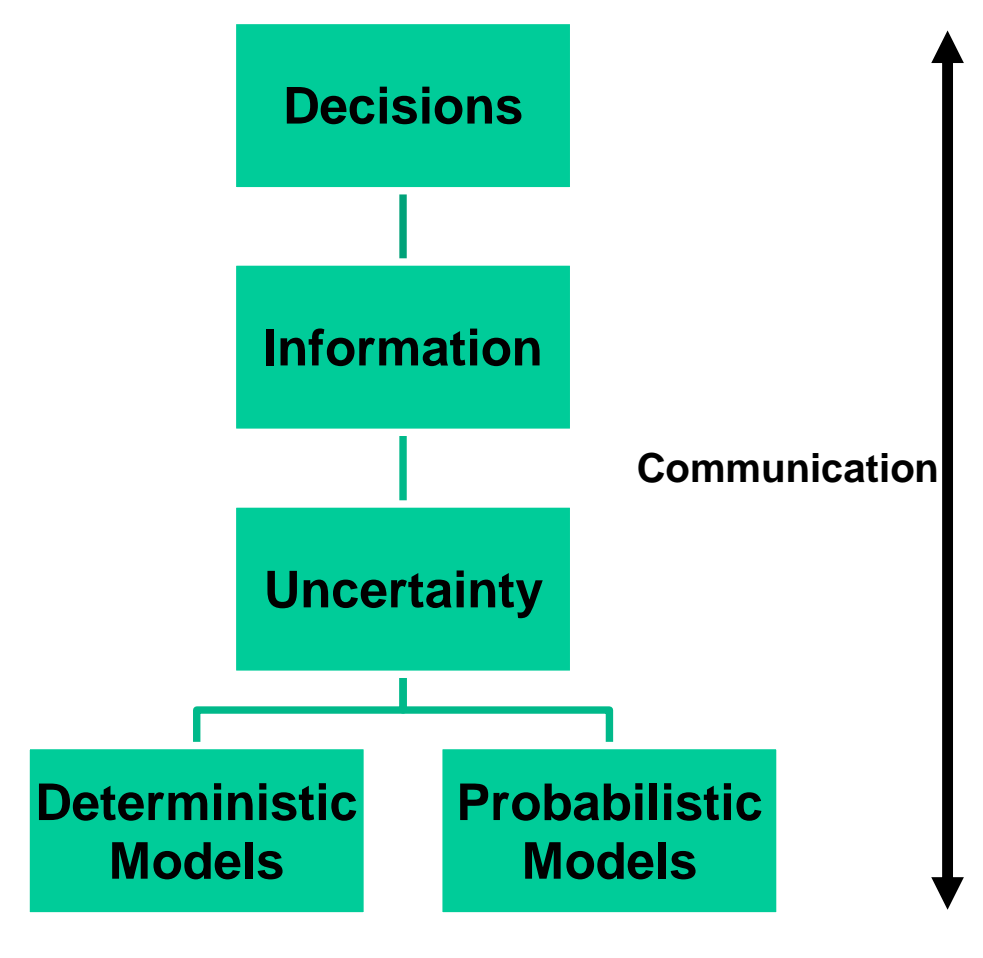




\section{Communicating the Uncertainties}

- Additional sources of information

- Effective Risk Communication (NUREG/BR-0308)

- The Nuclear Regulatory Commission's Guideline for External Risk Communication

- Effective Risk Communication (NUREG/BR-0318)

- Guideline for Internal Risk Communication

- LIC-504

- Documents uncertainties and technical basis for use by decision-makers 


\section{Communicating the Uncertainties}

- In the Davis-Besse post analysis, two clad failure models were available

- What would have happened if decision-makers were told that the initial model was fine?

- Their info would have been clad failure pressure of 6500 psi

- Probability of failure at 2150 psig would have been in the 1E-6 range

- They would have concluded clad failure unlikely (with high confidence)

- This is the wrong answer (with high confidence!)

- A lack of diversity of opinions about what model to apply blocks critical thinking

- Need to ask questions such as

- How do I know what I "know"?

- How wrong can I be if I guess wrong about what I don't know?

- Need to discuss with the decision-makers about how much we believe 


\section{Communicating the Uncertainties}

- When discussing models, conditions, or approaches, we might consider alternatives if available model is

- Old or obsolete

- New (unvalidated) or unfamiliar

- Not applicable for specific issue

- Of limited scope

- Overly optimistic/overly pessimistic

- Opaque (assumptions not clear, modules unexplained)

- Difficult or expensive to use

- Does not provide uncertainty or other required output 


\section{Communicating the Uncertainties}

- One roadblock to effective communication is bias

- How do we overcome bias?

- To reduce bias, one must be actively attempting to do so

- For example, rather than thinking "How does this support my beliefs?" think "What might this mean?"

- When performing an analysis, suspend early judgment or expectations

- Everyone has subconscious biases...

- But a questioning attitude can reduce these

- Questions to think about when critically thinking include:

- What is meant by

- How did you come to that conclusion?

- Why do you think that is correct?

- What are your sources?

- What assumptions drive that conclusion?

- What happens if this is incorrect?

- What is an alternate explanation for this phenomenon? 


\section{Communicating the Uncertainties}

- Critical thinking provides a useful communication process

- List results from all relevant models and collect arguments, data, and analysis supporting each

- These results may be probabilistic, graphical, outcomes of sensitivities, or reality checks

- Break the conclusions into key statements

- Then note additional implications from these

- Examine statements and implications for internal contradictions

- Describe the results, including plausibility, of conflicting or alternative models

- Models with strong support should provide more evidence than weaker models

- Require sufficient support to justify any claims or assumptions, otherwise, ignore these when making decisions

Critical thinking is a process of critiquing statements, examining the evidence/model, and forming judgments about results 


\section{Communicating the Uncertainties}

- Be committed to an open and objective process that recognizes validity of multiple perspectives in keeping with NRC's principles of good regulation - independent, open, efficient, clear, and reliable

- Use a flexible, problem-solving approach to meet needs of the agency, specific stakeholders, and situations

- Identify proactive steps to develop trust and credibility, raise awareness, and build relationships

- Be broadly supportive within the organization (not just within a specialized function)

- Emphasize two-way communication among risk analysts, engineers, decision makers, and the public about data, assumptions, values, etc.

NUREG/CR-6840 - The Technical Basis for the NRC's Guidelines for External Risk Communication 


\section{Communicating the Uncertainties}

- How can we do this better?

- Be more proactive

- Listening to collaborator needs

- Understand everyone's role in the decision process

- Commit resources

- Strive for consistency (common understanding)

- Management will be responsible for considering uncertainties that are communicated

- Do you have any examples you would like to share?

NUREG/CR-6840 - The Technical Basis for the NRC's Guidelines for External Risk Communication 


\section{CASE STUDIES}

Challenger

Davis-Besse vessel head wastage 


\section{CHALLENGER}




\section{Results of Retrospective Analysis on Shuttle Risk}

Source: Shuttle Risk Progression: Use of the Shuttle Probabilistic Risk Assessment (PRA) to Show Reliability Growth, Teri L Hamlin et al. (AIAA, 2010) (downloadable from http://ntrs.nasa.gov/archive/nasa/casi.ntrs.nasa.gov/20110004917_2011004008.pdf)

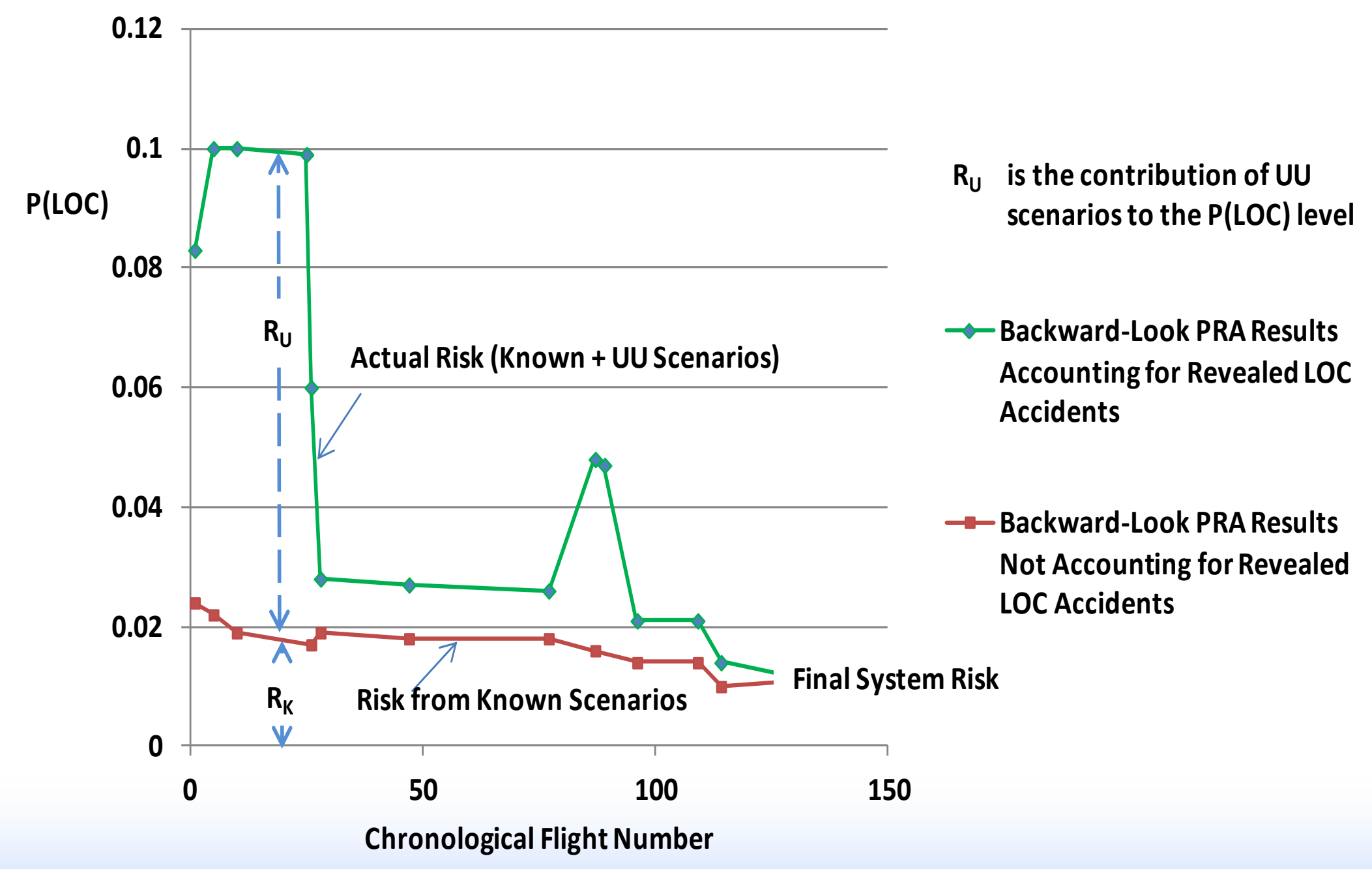




\section{NASA Challenger Example}

- Space Shuttle

Challenger O-rings

- How do we model failures when no experience at low temperatures

- "The decision to launch the Challenger was flawed"

- From the Report of the Presidential Commission on the Space Shuttle Challenger Accident

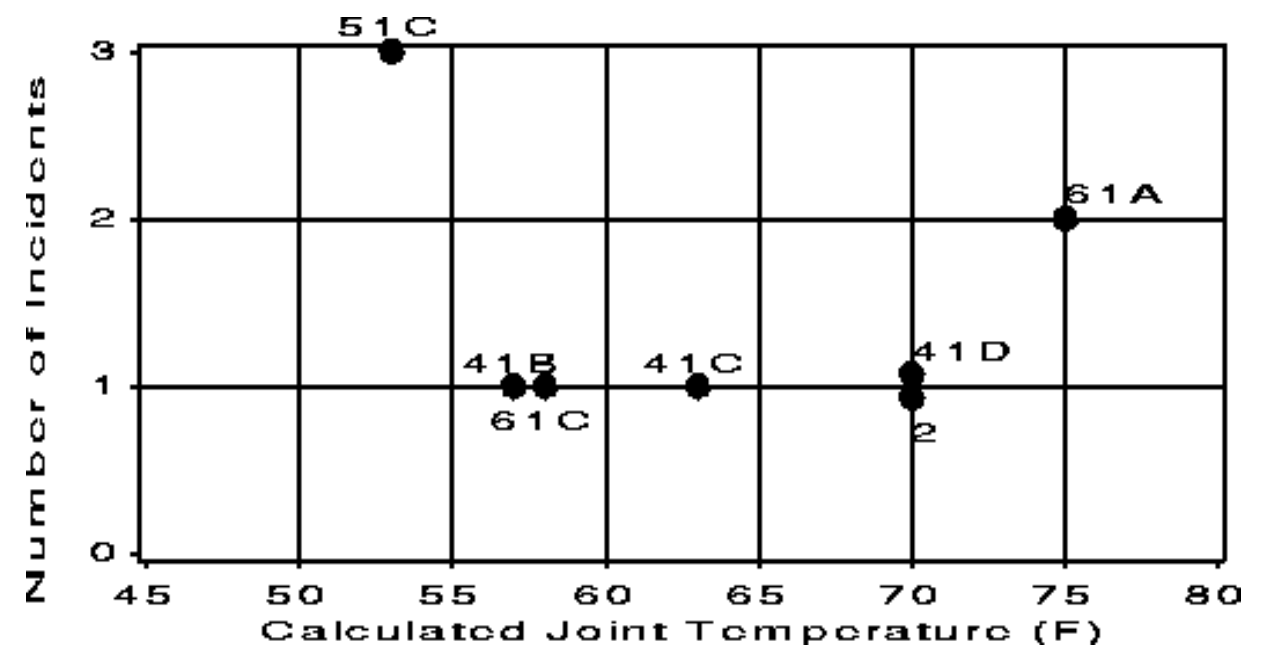

Morton Thiokol engineers focused only on failure events.

Failures occurred at different temperatures, leading to (incorrect) conclusion of no temperature dependence on o-ring performance 


\section{NASA Challenger Example}

- 1986 Challenger launch predicted at 26-29 degrees $F$

- How can we identify, characterize, and communicate uncertainties?

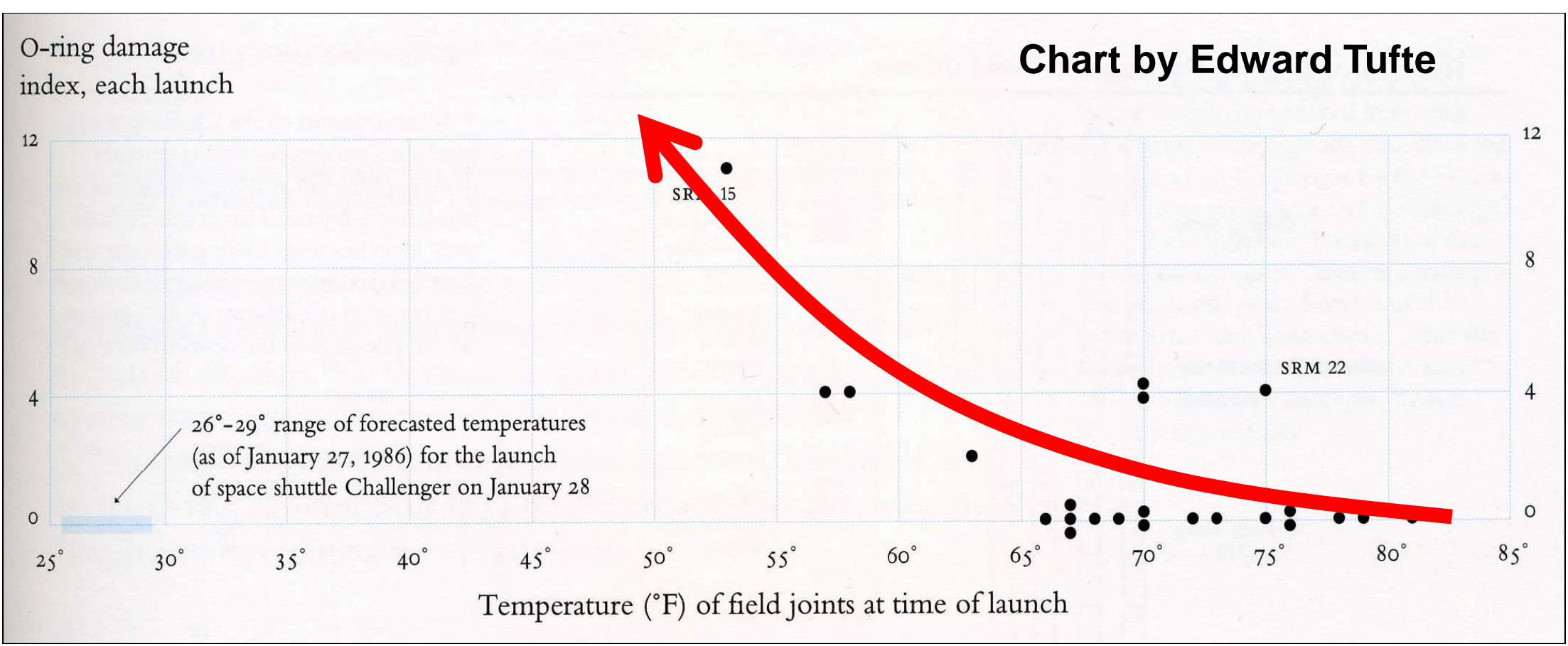

"Clear and precise seeing becomes as one with clear and precise thinking" Tufte 
Appendix F [of the Rogers Report]- Personal observations on the reliability of the Shuttle by R. P. Feynman

- A mathematical model was made to calculate erosion. This was a model based not on physical understanding but on empirical curve fitting. ... There is nothing much so wrong with this as believing the answer!

- Uncertainties appear everywhere. How strong the gas stream might be was unpredictable, it depended on holes formed in the putty. Blow-by showed that the ring might fail even though not, or only partially eroded through.

- The empirical formula was known to be uncertain, for it did not go directly through the very data points by which it was determined. There were a cloud of points some twice above, and some twice below the fitted curve, so erosions twice predicted were reasonable from that cause alone. ... 
Which of the previously-mentioned decision-making or modeling faults occurred in the handling of the Challenger event? What kinds of uncertainty operated?

- Previously Mentioned Modeling Deficiencies \& Decision-Making Traps:

- Anchoring

- Status quo

- Sunk costs

- Confirming evidence

- Estimating and forecasting

- Incompleteness

- Hypothesis space

- Model

- Normalization of Deviance 


\section{DAVIS-BESSE VESSEL HEAD WASTAGE}




\section{Davis-Besse Vessel Head Timeline}

Figure 3-1

Time Line Relating Significant Items of Interest

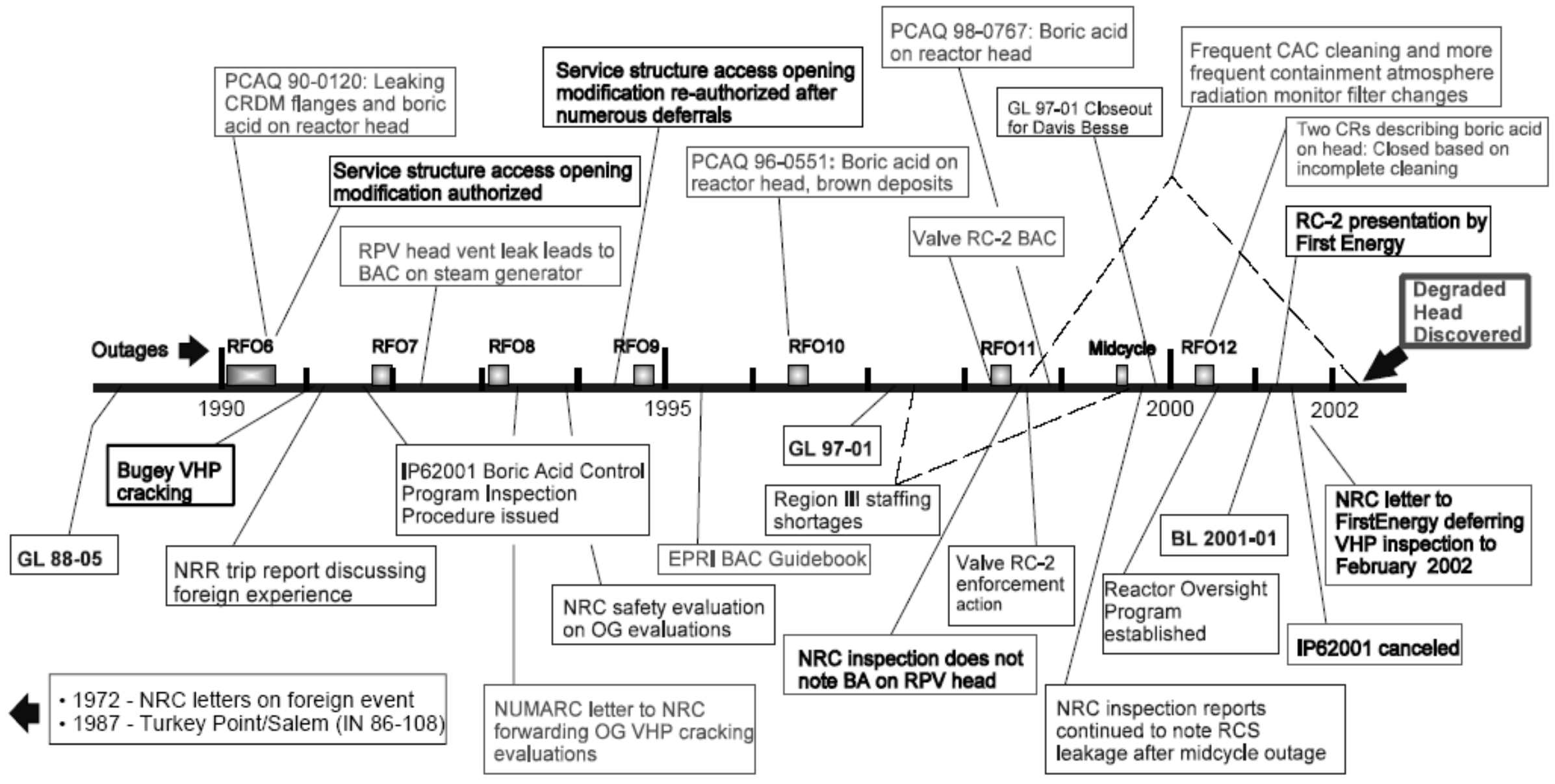

Davis-Besse Reactor Vessel Head Degradation

Lessons-learned Task Force Report 


\section{Indications: Leakage and Filter Replacements}

Appendix I

Time Line Relating Significant Events of Interest

Things are getting worse...

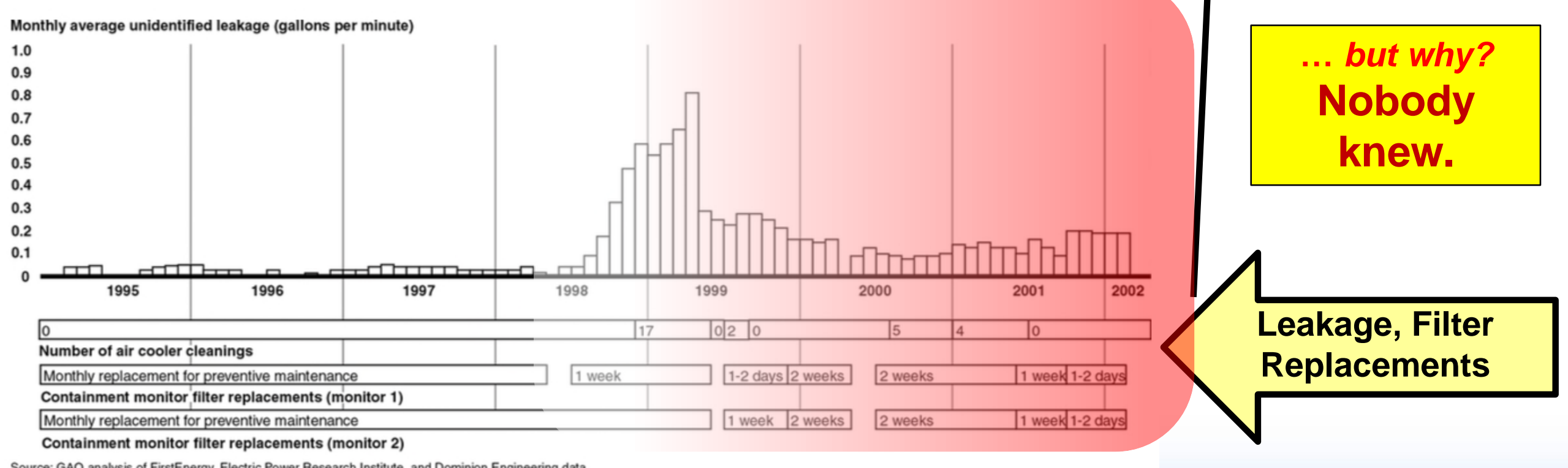

Source: GAO analysis of FirstEnergy, Electric Power Research Institute, and Dominion Engineering data. 


\section{Davis-Besse Vessel Head Example}

Figure 3-1

Time Line Relating Significant Items of Interest

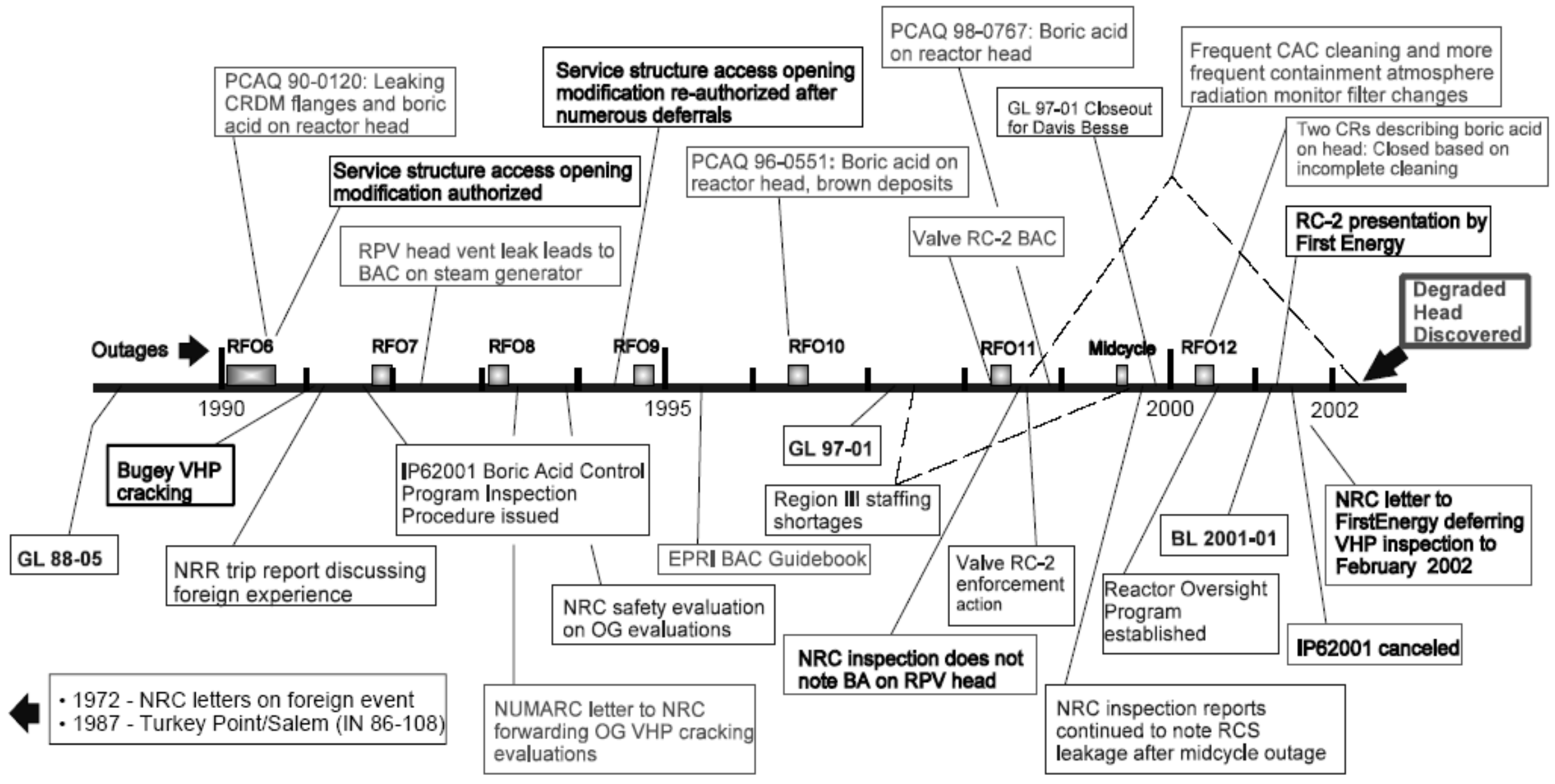

Davis-Besse Reactor Vessel Head Degradation

Lessons-learned Task Force Report 


\section{Background}

- Why is objective important?

- NRC tasked with ensuring public health and safety

- Need to be critical of modeling process

- Problems have occurred that undermine public confidence in this task

- For example, Davis-Besse vessel head corrosion led to a major degradation in safety ("significant precursor")

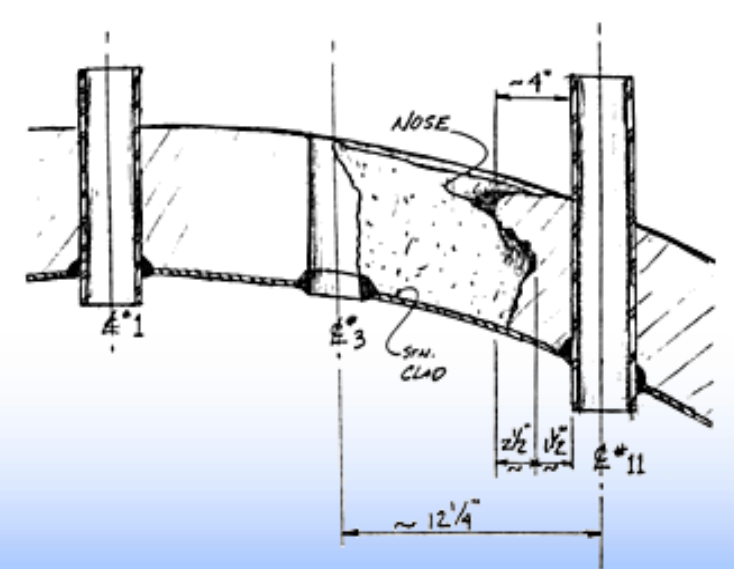




\section{Davis-Besse Vessel Head Example}

- Several breakdowns occurred when considering the Davis-Besse control rod drive nozzle probable leakage issue

1. Misguided focus on small leaks

- $\quad$ Large leaks through axial cracks were the expected result of degradation until small leaks were found (Oconee, $2001)$ to have resulted in OD circumferential cracking

- $\quad$ Thereafter, large leaks were not considered by analysts

2. Review staff was directed to not address probable technical specification violation

- $\quad$ Compliance with existing regulation one of the five criteria of NRC integrated decision making

3. Evidence of "groupthink"

- $\quad$ Prevailing thought was a small leak on a $600^{\circ} \mathrm{F}$ head would result in dry boric acid deposits that would not create significant wastage 


\section{Davis-Besse Vessel Head Example}

4. Lack of communication

- EPRI technical report* documenting rapid wastage due to boric acid leaks onto hot surfaces received at NRC around the same time as Davis-Besse risk-informed submittal

- Report was not reviewed until later

5. Lack of critical thinking about the process

- $\quad$ A check with a steam table shows that

- $0.1 \mathrm{gpm}$ leak leaves $0.05 \mathrm{gpm}$ of saturated water

- This water can remove heat by evaporation faster than it can be conducted through 6" of RPV steel (or even $1 / 4$ " of clad after wastage) over a 20 inch $^{2}$ area

- Consequently, boric acid never allowed to dry out 


\section{Davis-Besse Vessel Head Example}

6. Thought knew where leak was coming from

- Licensee believed all deposits seen on head came from flange leaks above the head

- There had always been flange leaks above the head...

- Thought this even though containment conditions had recently changed due to RCS leakage

- During post-event analysis (after 2002) did not consider clad cracking (did not apply knowledge from other events)

- Initial NRC and licensee modeling of bottom of the wastage cavity structural integrity did not consider stress corrosion cracking of clad

- These cracks were found in the laboratory after a year of analysis

- SCC of stainless steel in an oxygenated environment is a wellknown phenomena

- Did not understand effects of cracks on clad integrity

- Wrong failure mechanism model was assumed (based on tests with plate material) until ORNL obtained data of crack effects on clad material 


\section{Davis-Besse Vessel Head Example}

- Wrong model for clad failure evaluation

- Cracking was more extensive than first thought

- The originallybelieved failure mechanism (blue upper region) appears not applicable

- Later model (yellow

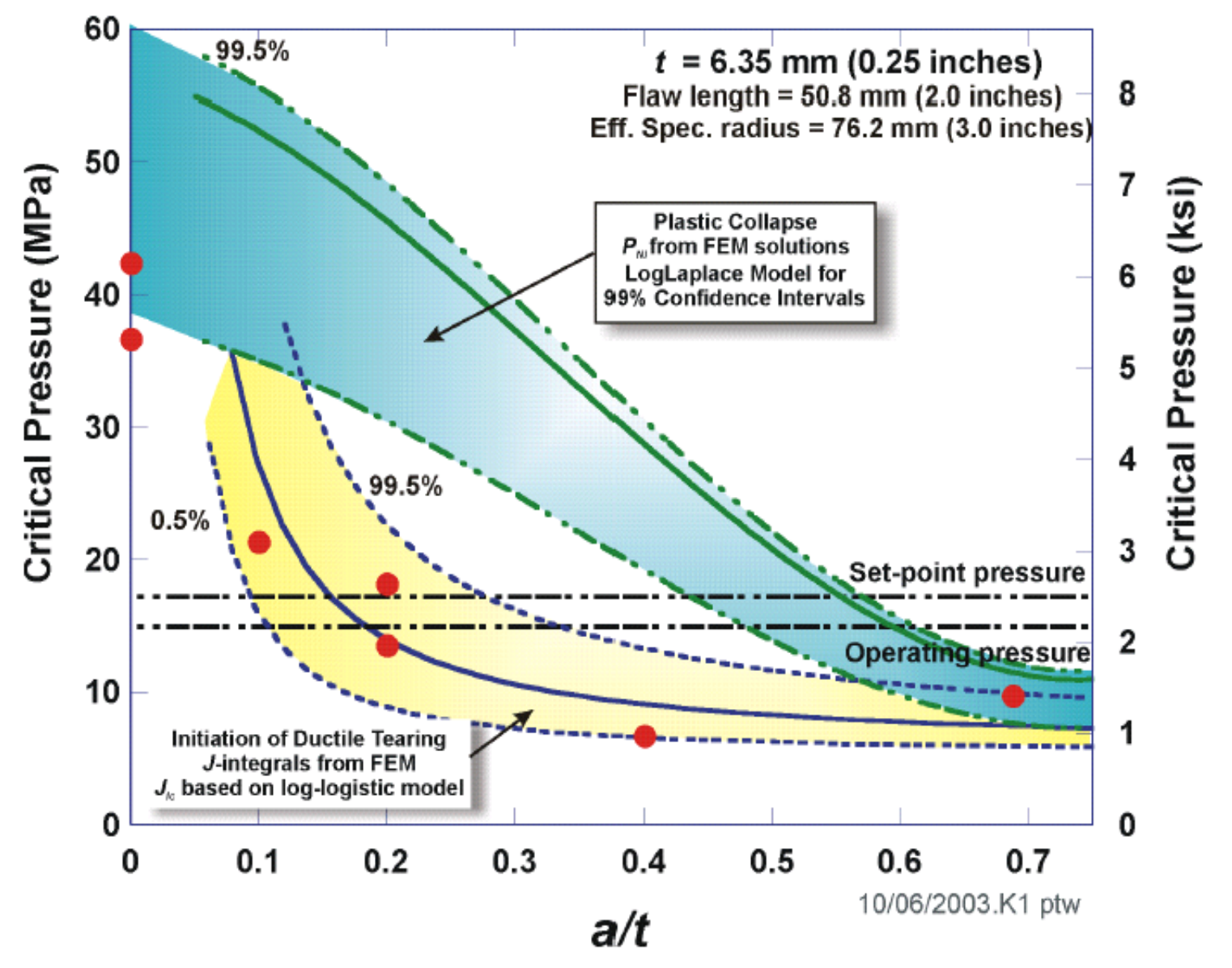
lower region) better fits observed behavior 


\section{Outcomes of Davis-Besse}

- Lessons learned task force identified a number of weaknesses in NRC practices

Including: failure to understand uncertainties and communication between modelers and decision-makers

"For future risk-informed decision-making actions involving passive components, the staff should provide decision-makers with a written assessment of the adequacy of the specific models used for the particular decision to be made" 


\section{Davis-Besse Issues}

- For Davis-Besse, boric acid leaking onto reactor vessel head judged not to be a concern

- This situation thought not to pose a problem since

- Previous inspections only identified small leaks, and Staff believed only large leaks would cause significant wastage

- Leaks were not considered a wastage issue because

- Large leaks dismissed because detection likely

- Small leaks dismissed as being too small to cause wastage

- Prompt and effective corrective actions would be taken to repair significant leaks

- Liquid boric acid incorrectly assumed to completely dry when deposited on surface of RPV

- Dry boric acid not rapidly corrosive 


\section{NRC's Actions to Oversee Davis-Besse Did Not Provide an Accurate Assessment of Safety at the Plant}

- NRC's inspections and assessments of FirstEnergy's operations should have but did not provide the agency with an accurate understanding of safety conditions at Davis-Besse, and thus NRC failed to identify or prevent the vessel head corrosion.

- Some NRC inspectors were aware of the indications of corrosion and leakage that could have alerted NRC to corrosion problems at the plant, but they did not have the knowledge to recognize the significance of this information. These problems were compounded by NRC's assessments of FirstEnergy that led the agency to believe FirstEnergy was a good performer and could or would successfully resolve problems before they became significant safety issues.

- More broadly, NRC had a range of information that could have identified and prevented the incident at Davis-Besse but did not effectively integrate it into its oversight. 


\section{LIC-504 Risk-Informed Decision-Making Process}

Technical Activities

Risk-Informed Activities

Communication Activities

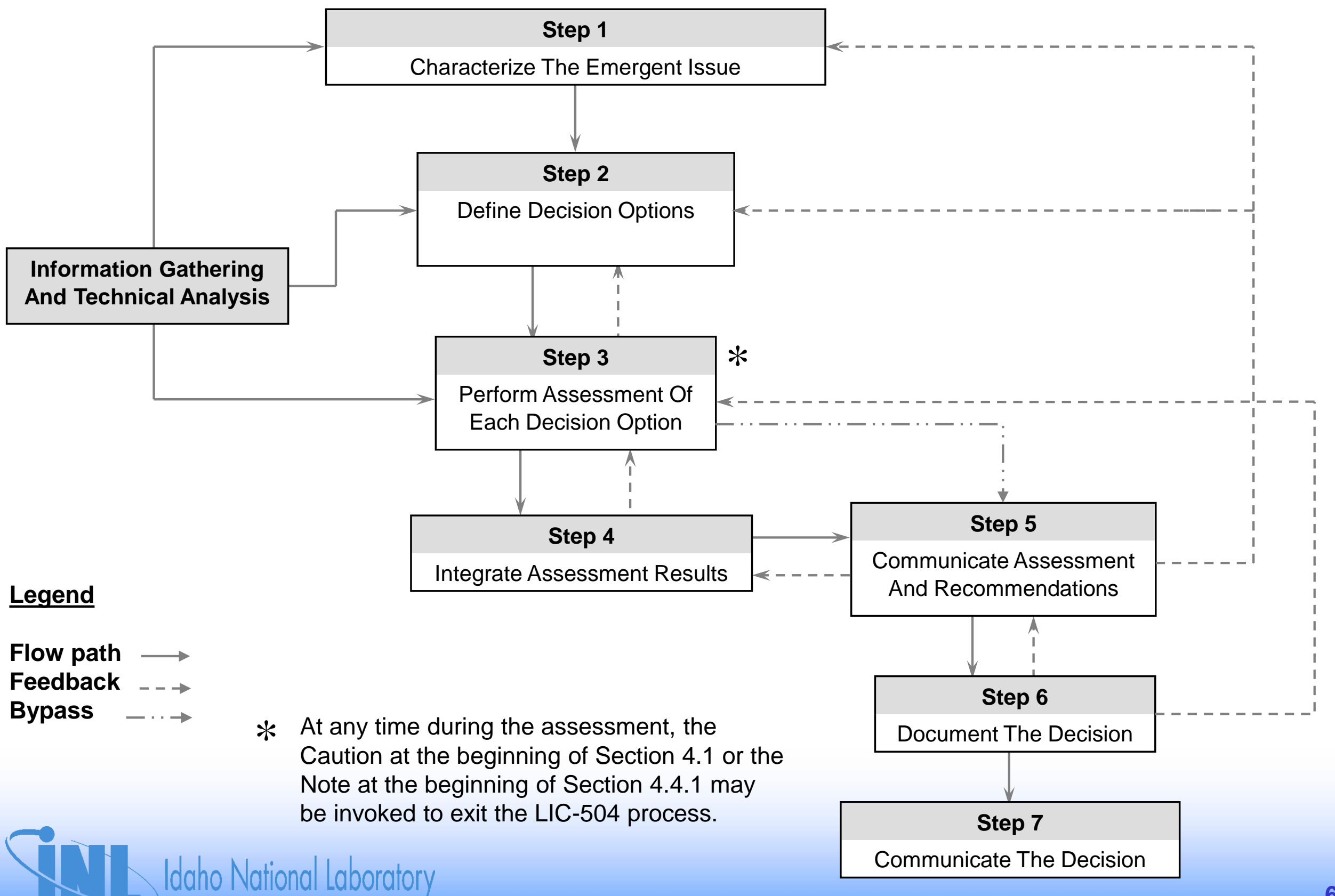




\section{LIC-504}

...GAO made the following two recommendations:

(2) Improve the U.S. Nuclear Regulatory Commission's (NRC's) use of probabilistic risk assessment (PRA) estimates in decision making by (1) ensuring that the risk estimates, uncertainties, and assumptions made in developing the estimates are fully defined, documented, and communicated to NRC decision makers, and (2) providing guidance to decision makers on how to consider the relative importance, validity, and reliability of quantitative risk estimates in conjunction with other qualitative safety-related factors.

\section{Which NRC decisions related to the Davis-Besse vessel-head issue would change under LIC-504?}


Which of the previously-mentioned decision-making or modeling faults occurred in the handling of the Davis-Besse wastage event?

- Previously Mentioned:

- Anchoring

- Status quo

- Sunk costs

- Confirming evidence

- Estimating and forecasting

- Incompleteness

- Hypothesis space

- Model

- Normalization of Deviance 


\section{CRITICAL THINKING}




\section{Basics}

Risk-informed decision-making requires critical thinking

- Adequate understanding of supporting models and analyses

- Including uncertainties

- Inadequate communications between analysts and decisionmakers contributes to poor decisions

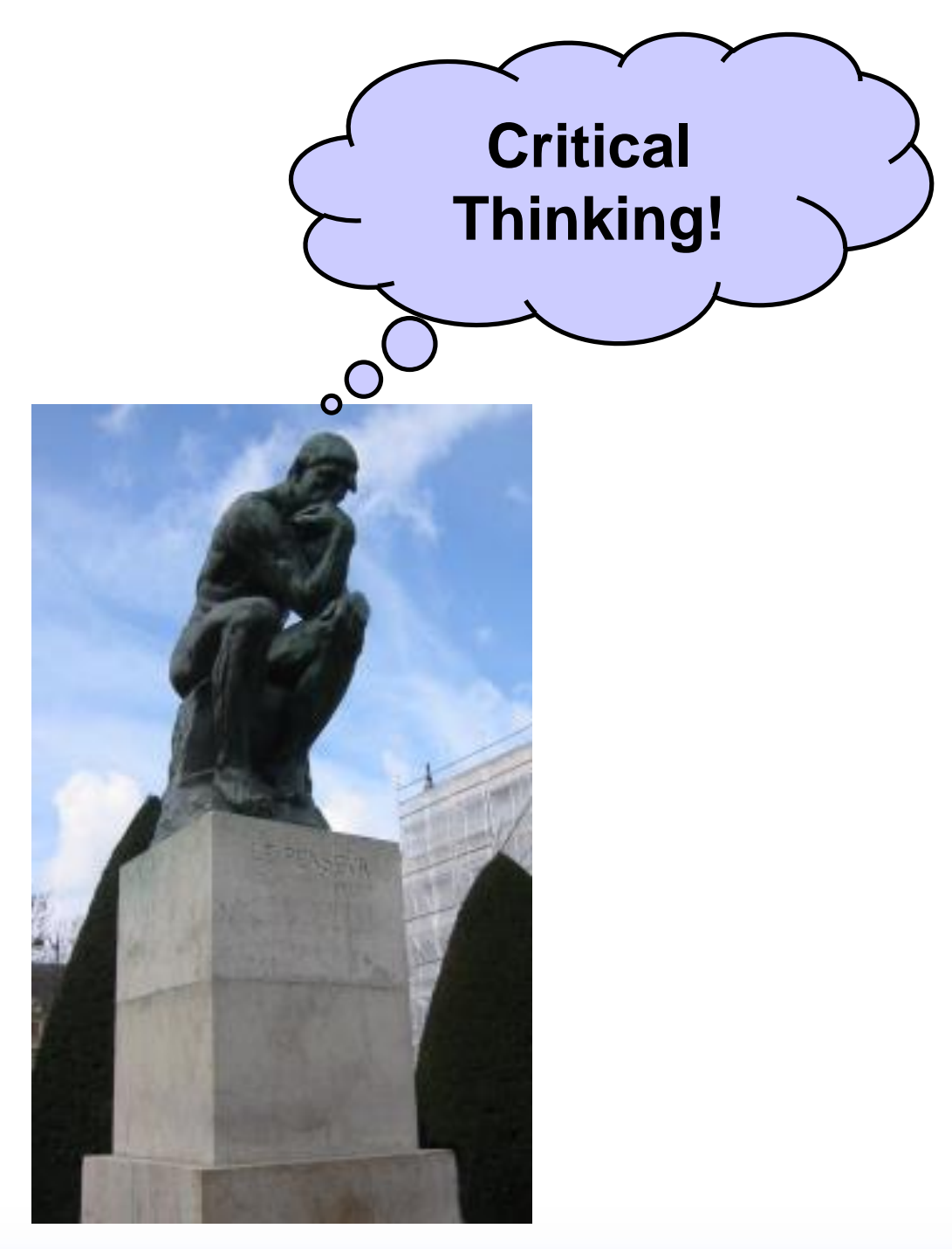




\section{Basics}

To facilitate effective decisions

- We need to understand the issues

- For each model and each decision

- Identify the uncertainties

- Characterize the uncertainties

- Communicate the uncertainties

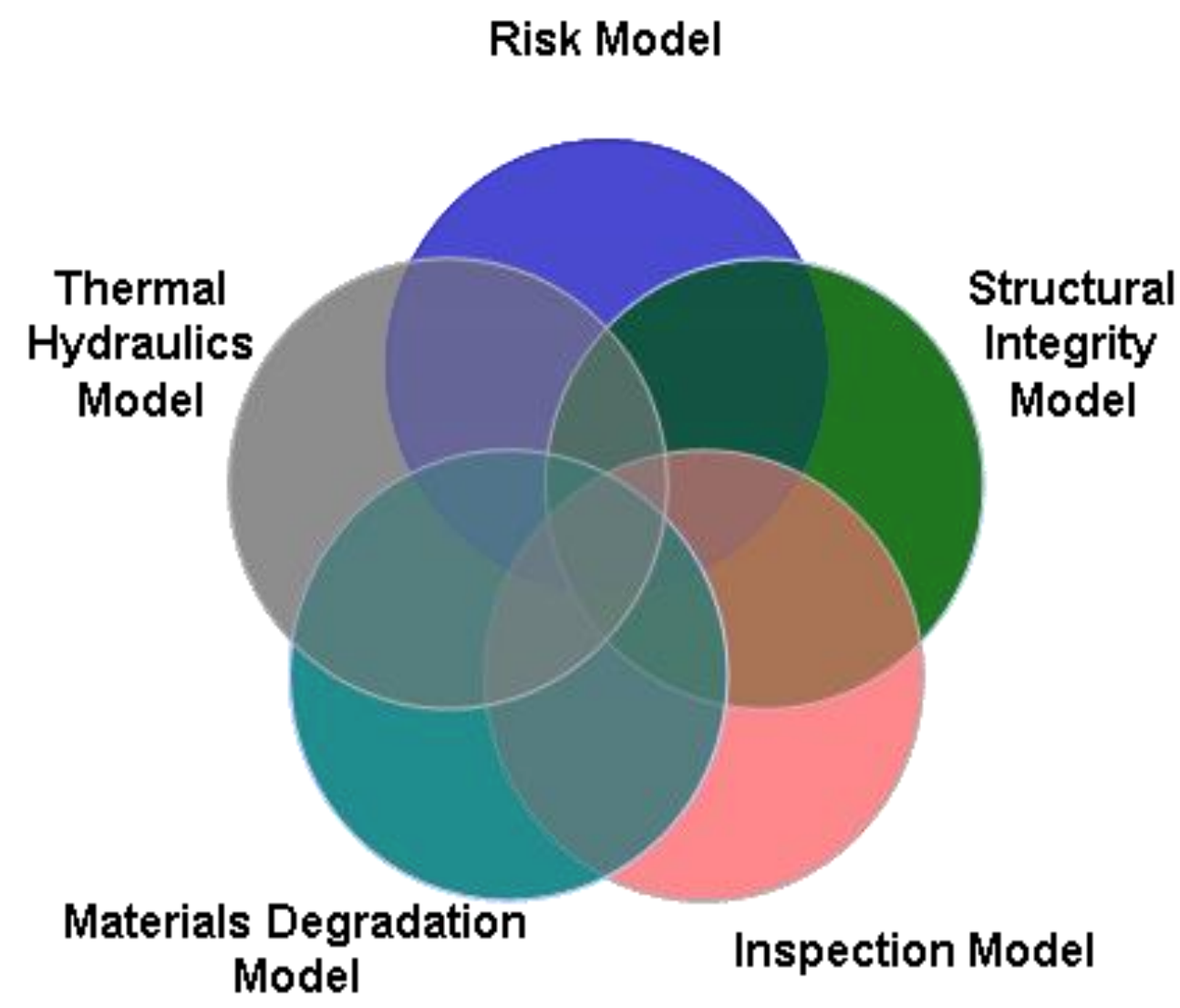

Effective decision-making requires integration of information from many sources 


\section{Workshop - Critical Thinking}

- The graph shows the number of people entering and leaving a building

- Answer the questions below:

1. During which minute did the most people enter the building?

2. During which minute did the most people leave the building?

3. During which minute were the most people in the building?

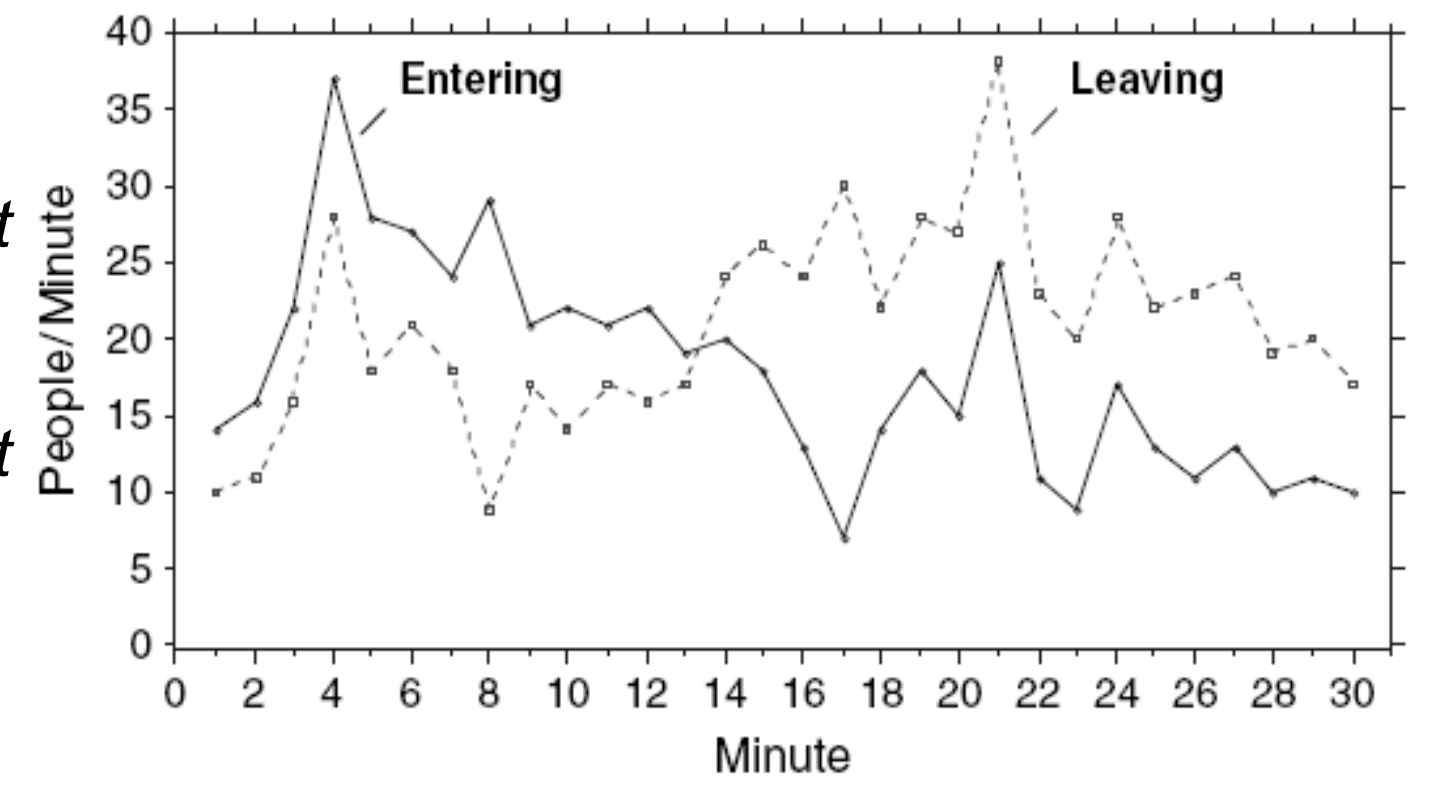

4. During which minute were the fewest people in the building?

From "All models are wrong: reflections on becoming a systems scientist," John Sterman 


\section{Good Decisions Require Good Input}

- Analysis results

- Need to be relevant to issue being decided

- Need to be clearly understood by decision-maker

- Need to include information on uncertainties

- Identification

- Characterization

- Communication is key element 


\section{Effective Issue Analysis Process}

- Management and staff need to develop and document a common understanding of the issue including:

- Definition of issue

i.e., defining decision to be made

- Development of decision-making approach

- Selection of acceptance criteria

- Specification of the technical / risk analyses to be performed

- Role(s) of the technical analysis

- Define the boundary conditions for the analysis 


\section{Analyses Support Decision-Making}

- Analyses need to provide basis for concluding that...

- Regulatory position provides reasonable assurance of adequate protection of public health and safety ...

- .... Without imposing undue burden on licensees

- Technical basis for the decision should not over-rely on any single evidence type (especially not PRA)

Based on Figure 2, "Principles of risk-informed integrated decision-making," from RG 1.174, "AN APPROACH FOR USING PROBABILISTIC RISK ASSESSMENT IN RISK-INFORMED DECISIONS ON PLANT SPECIFIC CHANGES TO THE LICENSING BASIS"

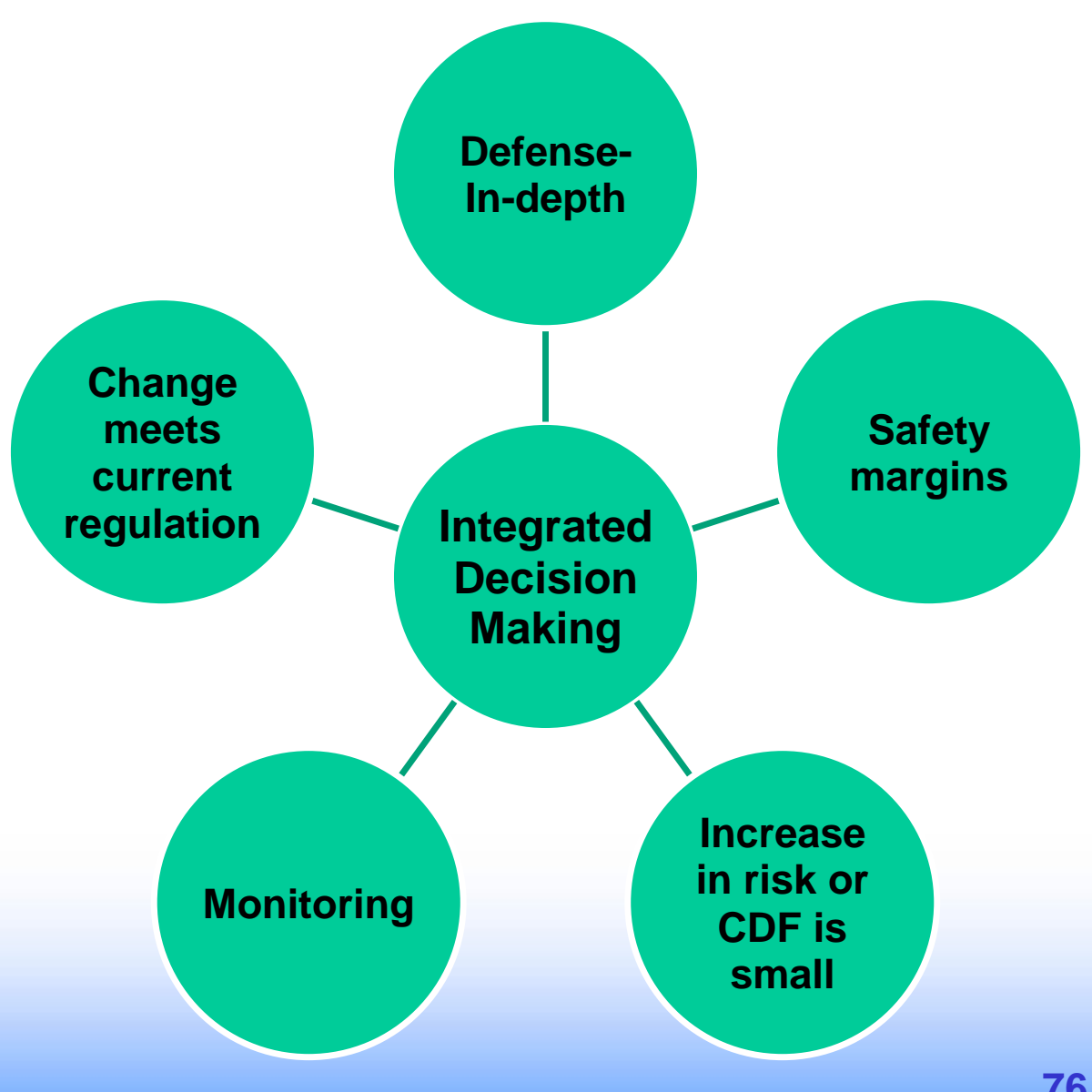




\section{Definition of Issue}

- What is impact on Plant

- SSCs or functions affected

- Changes or departures (e.g., 10 CFR 50.59)

- Need to assess potential for regulatory concern of degradation mechanism (via RG-1.174 principles)

- Violates current regulations?

- Reduces defense in depth?

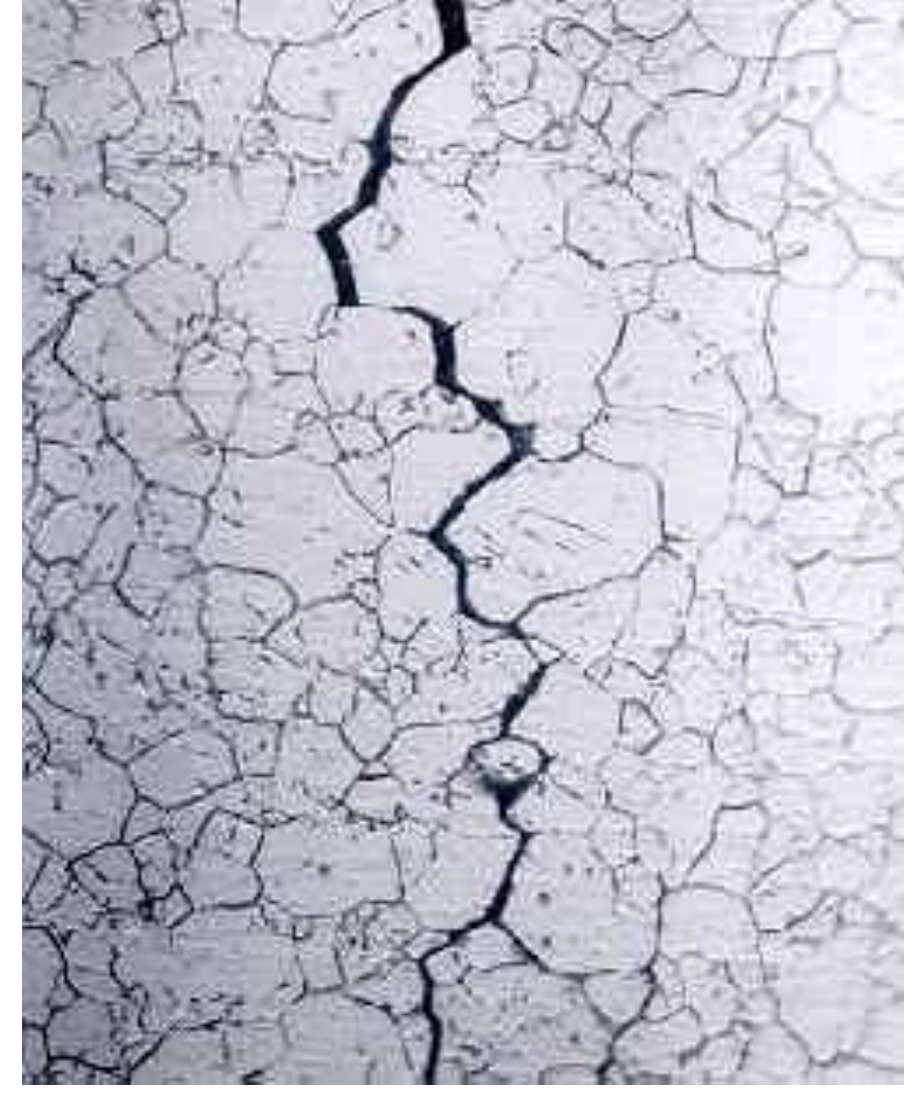

- Reduces safety margin?

- Significantly increases risk?

- Monitoring/performance measures?

- Adequate knowledge of current plant conditions?

- For these, need to consider uncertainty and performance monitoring Analyst needs to question the basis for conclusions regarding each principle above to determine if it is sufficiently complete and accurate to produce a robust answer 


\section{Definition of the Technical Issue}

- To understand how technical issues should be defined, we need to understand how the results will be used

- According to J. Diamond ("Collapse - How Societies Choose to Fail or Succeed" 2005)

- Failure to anticipate a problem

- Failure to perceive it once it has arisen

- Failure to attempt to solve it after it has been perceived

- Failure to succeed in attempts to solve it

- Davis-Besse incident scored high on these 


\section{Definition of the Technical Issue}

- Failure to anticipate a problem

- Prejudging or ignoring a issue, such as ruling out a failure mechanism, is a classic way to facilitate spectacular failures

- In Davis-Besse, large leaks were not considered coupled with belief of drying boric acid provided boundary conditions for material degradation

- Precluding events or conditions, even if they are unlikely, makes risk-informed decision making impossible

- Consequently, one key consideration when defining the issue at hand is to consider all possibilities

- With a questioning attitude, critical thinking involves acquiring information and evaluating it to reach a well-justified definition of the problem 


\section{Selection of Acceptance Criteria}

- In making a [risk-informed] regulatory decision

- Risk insights are integrated with defense-in-depth and safety margins considerations

- Degree to which risk insights play a role is application dependent

- Quantitative risk results from PRA...are generally supplemented by qualitative risk insights and traditional engineering analysis

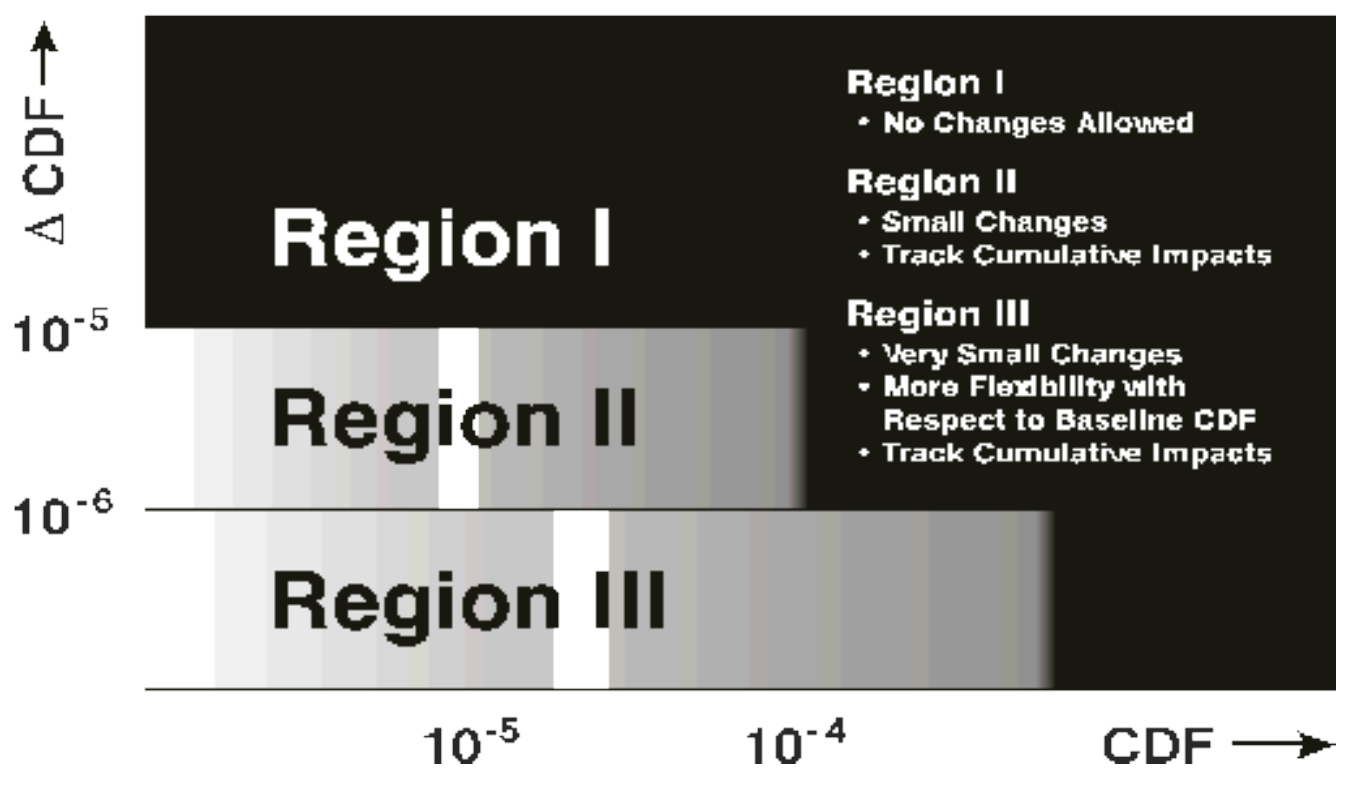

SECY-00-0162 


\section{Selection of Acceptance Criteria}

- Acceptance criteria are multidimensional since process has five facets

- Criteria are a blend of deterministic and probabilistic

- For example, meeting current regulation may be yes/no or probabilistic (Maintenance Rule)

- The risk metric (CDF) is probabilistic

- Different processes will have different criteria

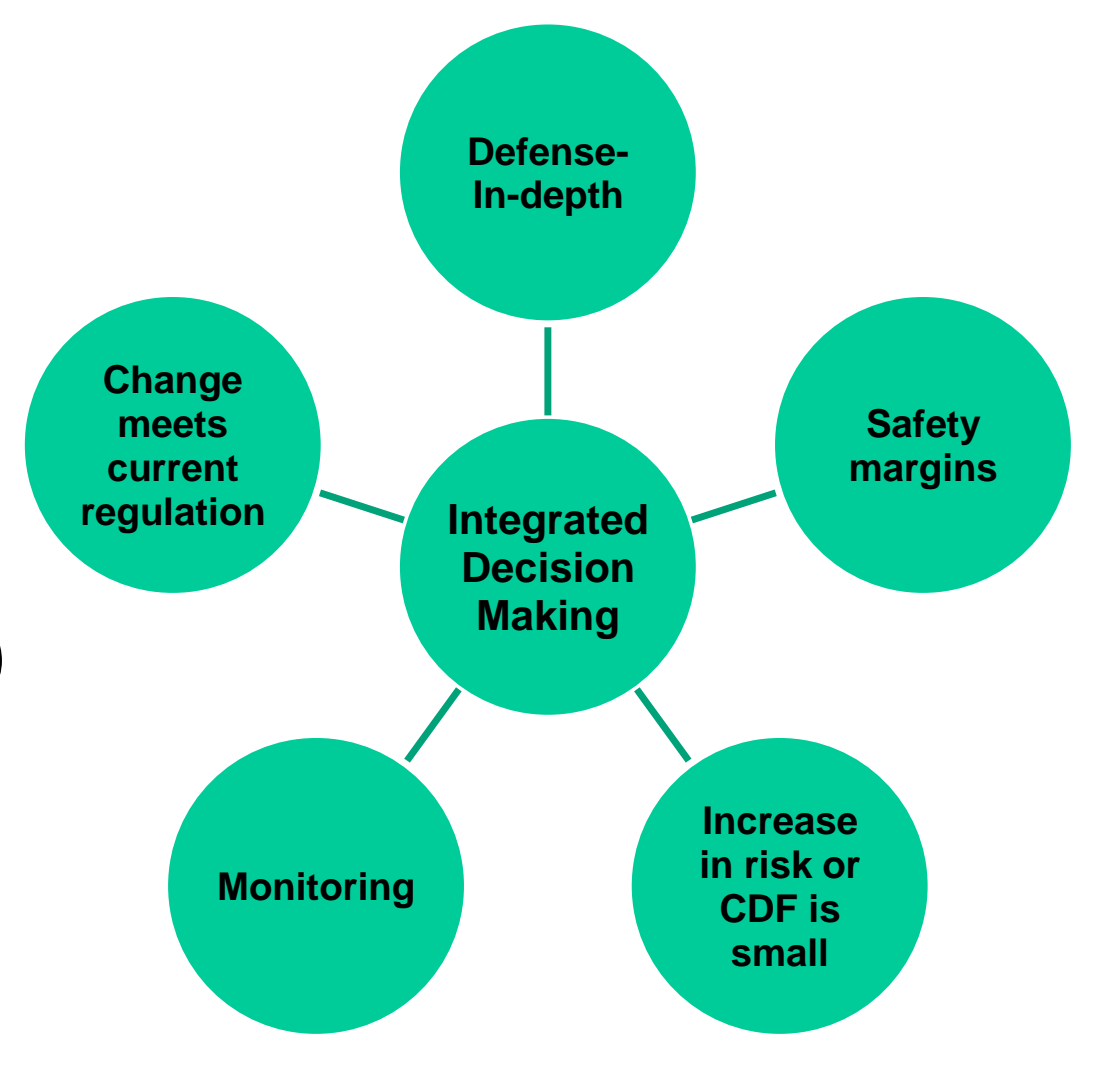

- Ranges from deterministic to probabilistic 


\section{Role of Technical Evaluations}

- The potential for regulatory concern is addressed by modeling and understanding:

- Degradation mechanism

- Structural integrity effects

- Efficacy of inspections

- Consequences of potential structural failures on plant systems/functions

- Effects of system failures on risk

The analyst needs to question the basis for each step of this assessment to determine whether it is sufficiently complete and accurate to produce a robust answer 


\section{Technical Evaluation Integrates Models}

- Our different model types bring relevant information into the process

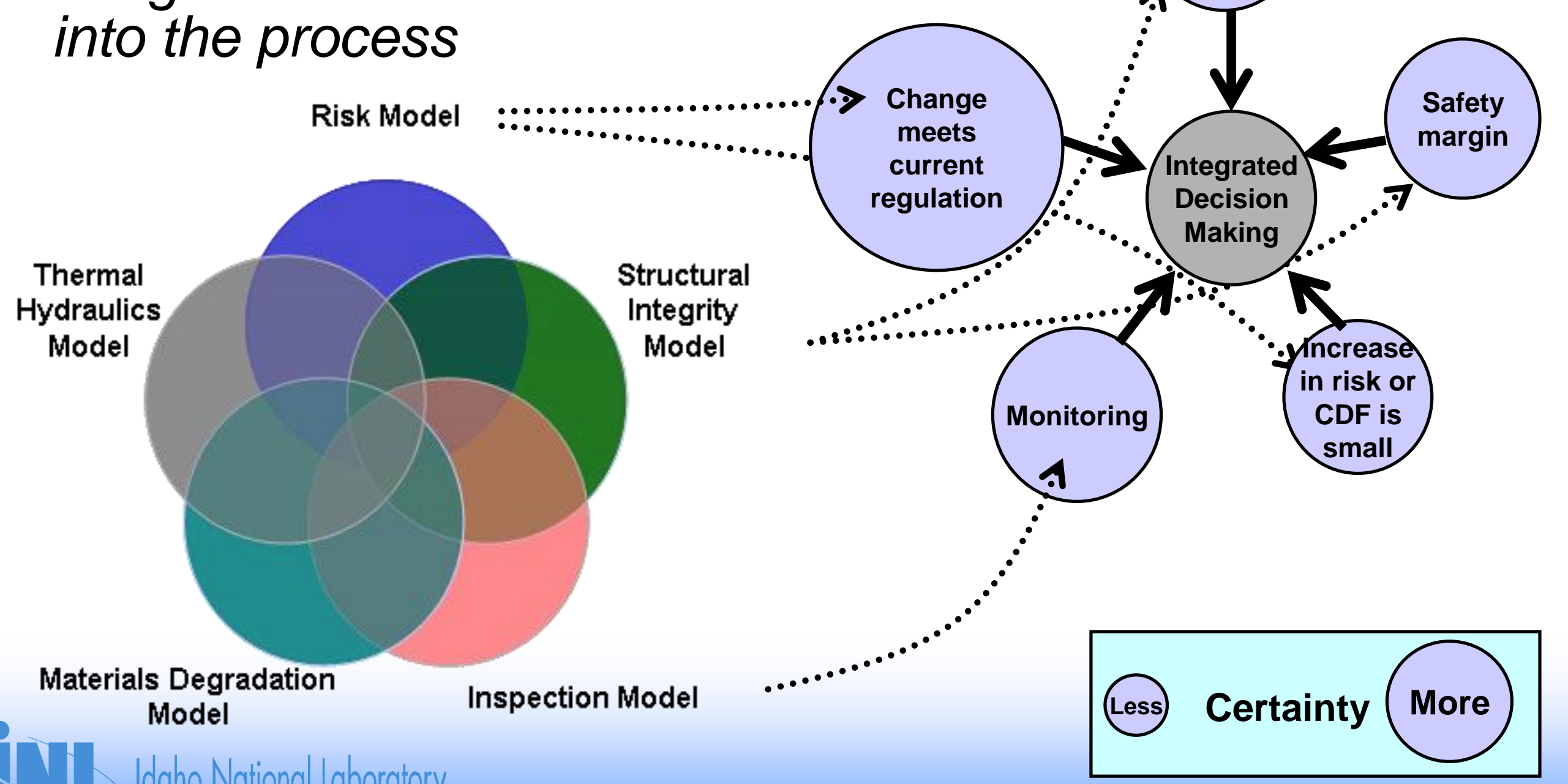




\section{Technical Evaluation}

- The subject of the analysis requires critical thought

- Should reflect purpose of the analysis

- Are we evaluating a single plant

- Or, are we considering the entire industry fleet

- Uncertainty on parameters in our model can reflect either

- Statistical confidence on a single "averaged" value

- Data applies to a specific plant or single application

- Variability among a population

- Multiple data sets used to represent many possible values of a parameter (one for each member in a population) 


\section{Understanding the Role of Analysis}

- The analyst must consider all models and processes

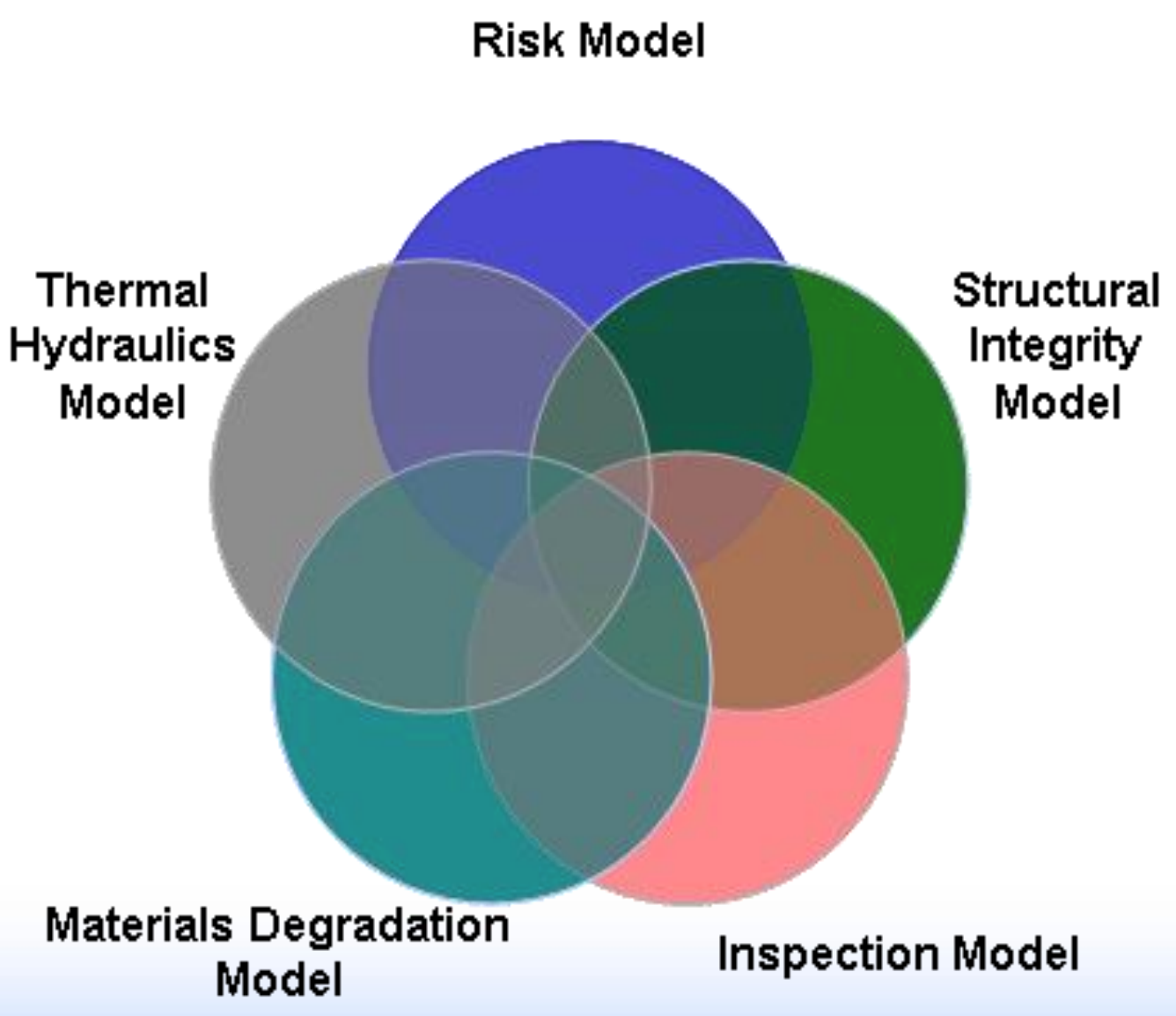




\section{Understanding the Role of Analysis}

- The rate of corrosion at Davis-Besse was specific to that plant

- If we had information on corrosion issues at many plants, what would we do with information for our analysis?

- Issue of parameter uncertainty versus plant-to-plant variability is key to many analyses

- Plant-specific parameter uncertainty is appropriate for producing plantspecific results

- From the loss of offsite power frequency (23 plants) we can obtain an average frequency

- For what kinds of analysis should I use the "average" frequency?

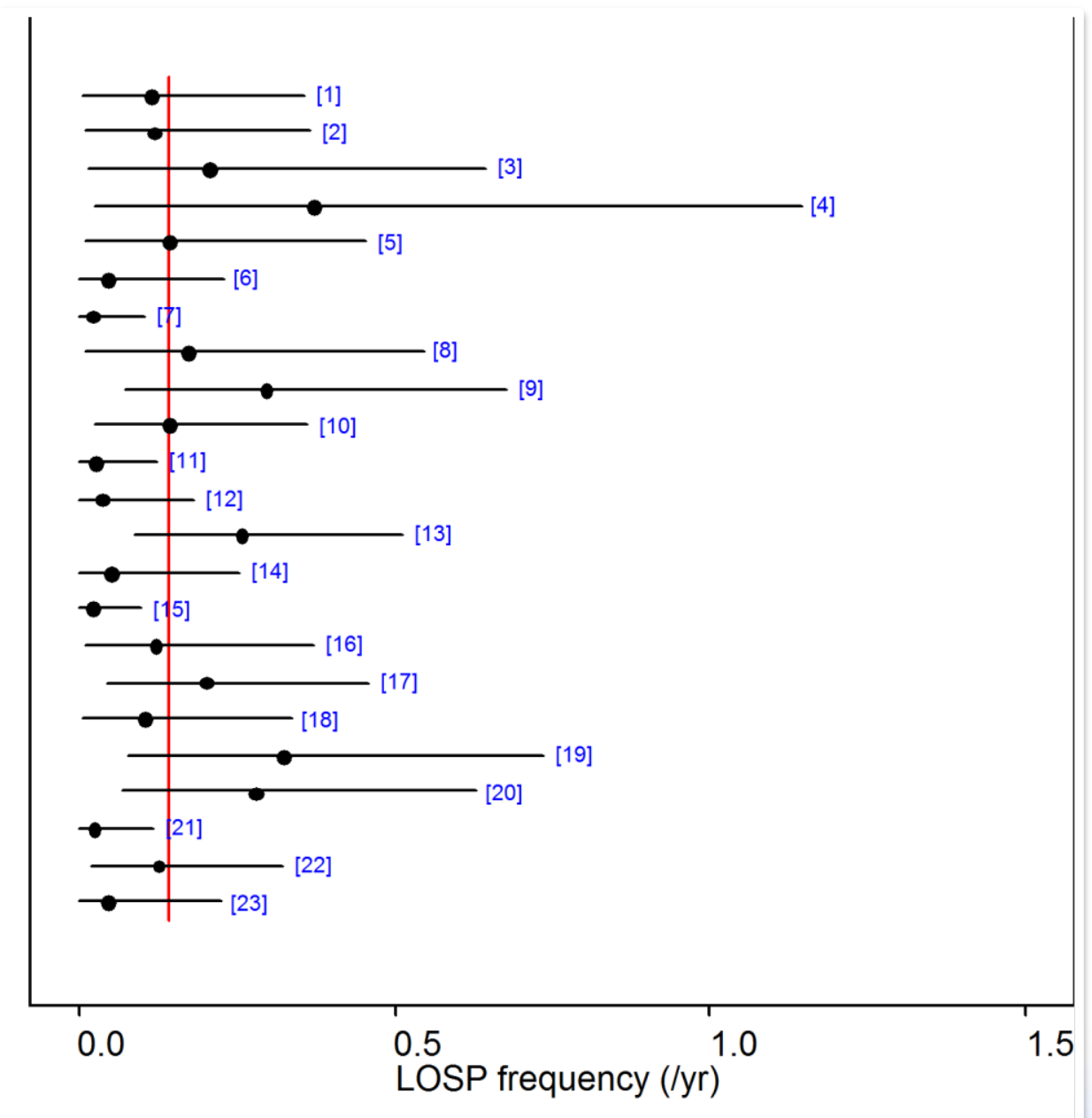




\section{Understanding the Role of Analysis}

- Sometimes, population-wide variability is used instead of plantspecific uncertainties for an "example plant" calculation

- This probability distribution of the variability can be interpreted as probability levels for individual plants not exceeding specific values

- Does not specify the specific plant's parameter values

- However, if variability and plant-specific parameter uncertainties are mixed in the same analysis, then

- Mean of the results may be less than the mean for the "bounding plant"

- A "bounding plant" is that with the highest results, where results are obtained by using its plant-specific uncertainties for all parameters

- In other words, simply lumping everything together with the desire to "bound" all possible outcomes backfires since results in middle of the population are reinforced by other near-average plants 


\section{Understanding the Role of Analysis}

- In addition to population variability, we may need to consider time-based trends

- For example, evaluating corrosion rate $(\lambda)$ for seven years

- Graphical constructs can supplement numerical ones

- Graph indicates apparent decreasing trend over time

- The what and how of the analysis will vary from issue to issue

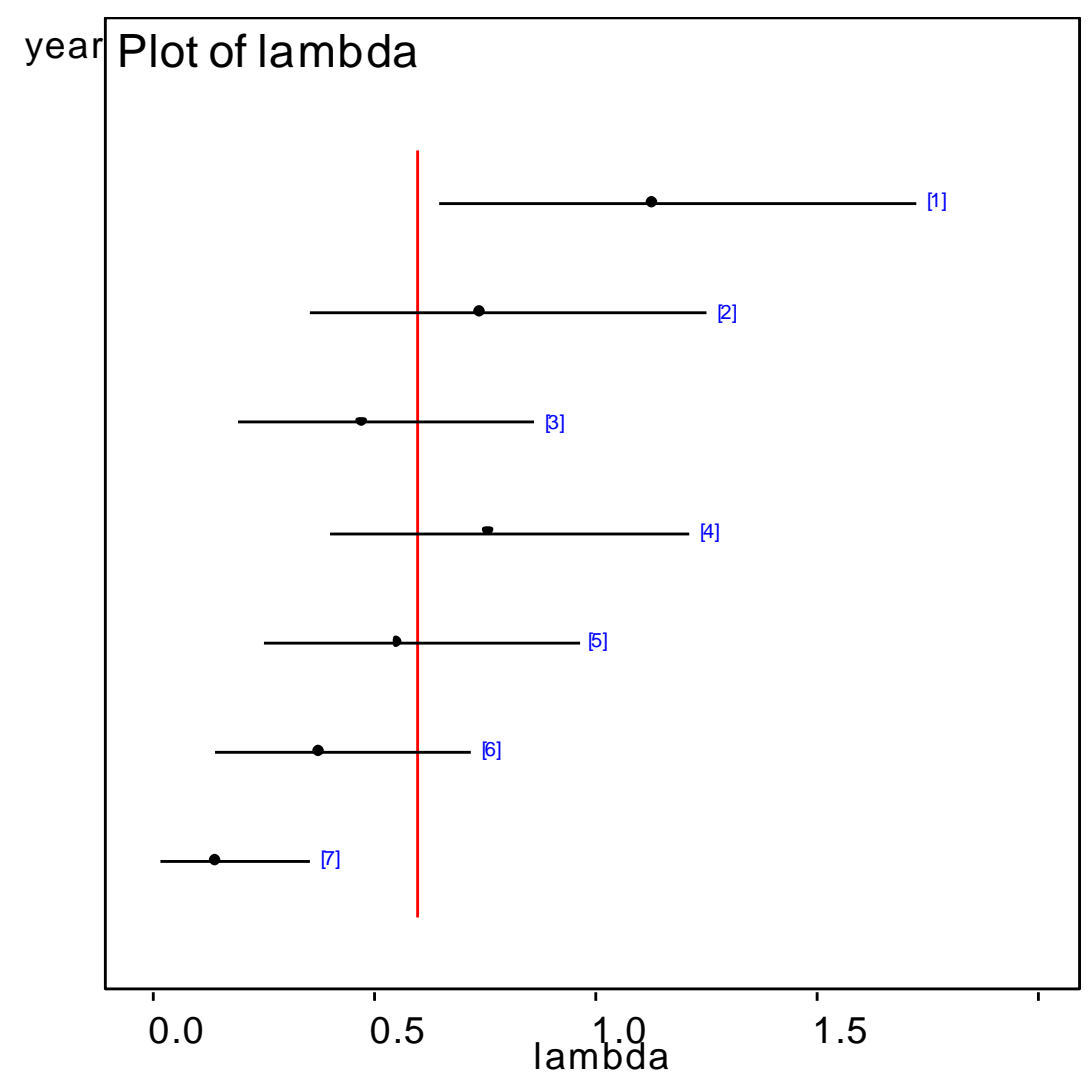




\section{Analyst's Responsibility}

- Analyses need to be developed in context with consideration and understanding of uncertainties

- These uncertainties are coming from both YOUR analyses and others (including those outside the NRC)

- Uncertainty treatment requires

- Effective interaction among analysis team members

- Critical thinking and a questioning attitude

- Past analyses have suffered from a lack of this thoroughness

- There are many sources of uncertainties that need to be considered

- For example: lack of data, misleading data, competing failure models, lack of understanding of processes, extrapolation, bias, ...

- Analyst needs to understand how results will be used in order to understand and communicate uncertainties

- Requires increased interaction among different technical disciplines, PRA integrators, and decision makers 


\section{Analyst's Responsibility}

- While this course focuses on raising the awareness of uncertainty in modeling and decisions, ...

- Detailed information on these topics and processes are found elsewhere

- For example, in other $N R C$ training courses

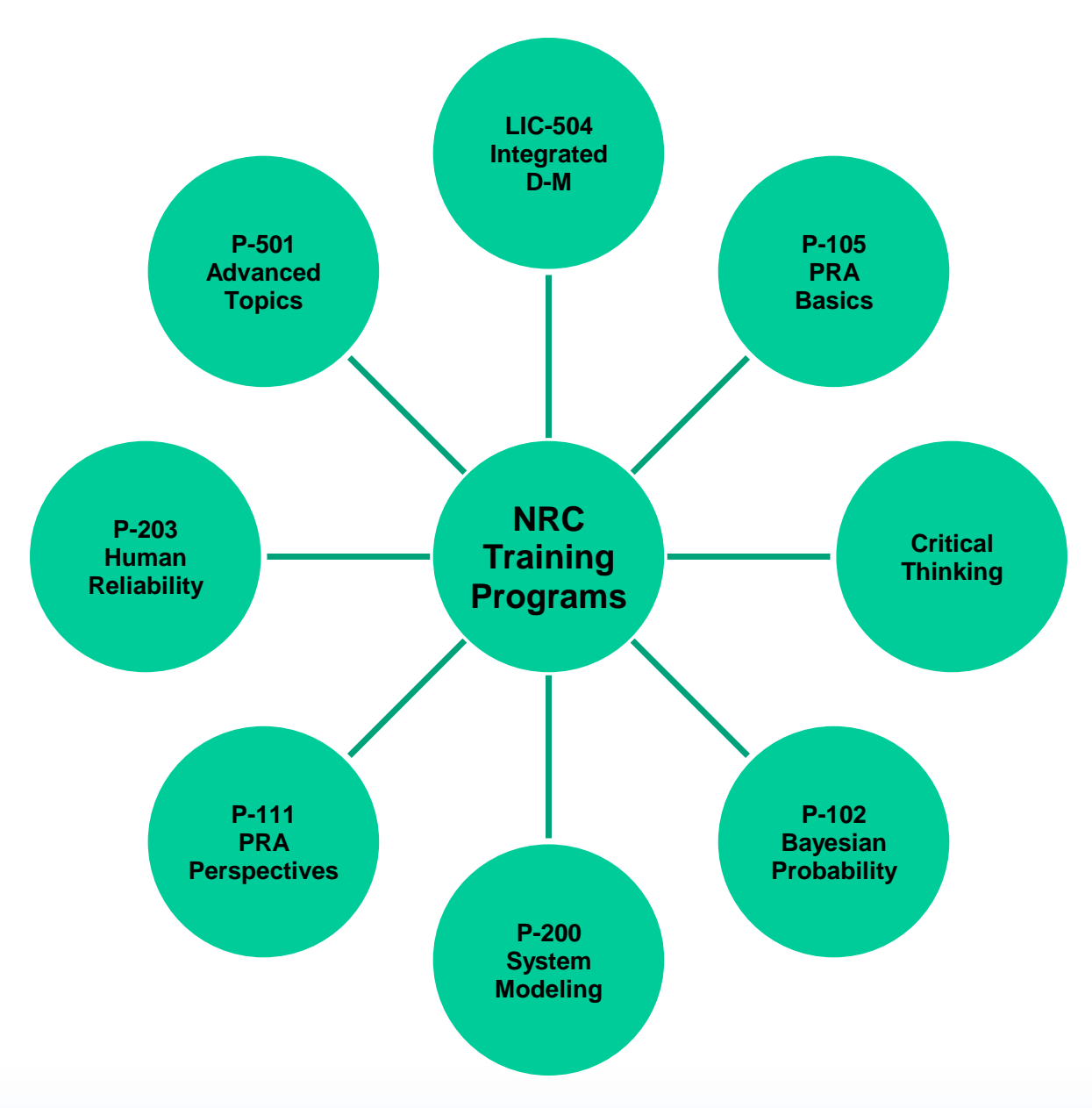




\section{Good Decisions Need More Than Good Technical Analyses}

- Decision-makers need to be "educated" about analyses

- Assumptions

- Boundary conditions

- Limitations

- Uncertainties

- Inadequate communication/education leads to lessthan-ideal decisions 


\section{Failures in Decision-Making (DM)}

- NASA Challenger

- Data interpreted without seeing temperature relationship

- Davis-Besse

- Numerous issues and failures in the process

- NASA Columbia

- Believed foam not an issue

- Focused on other impacts

- Fukushima

- Relied on "Tsunami folklore"

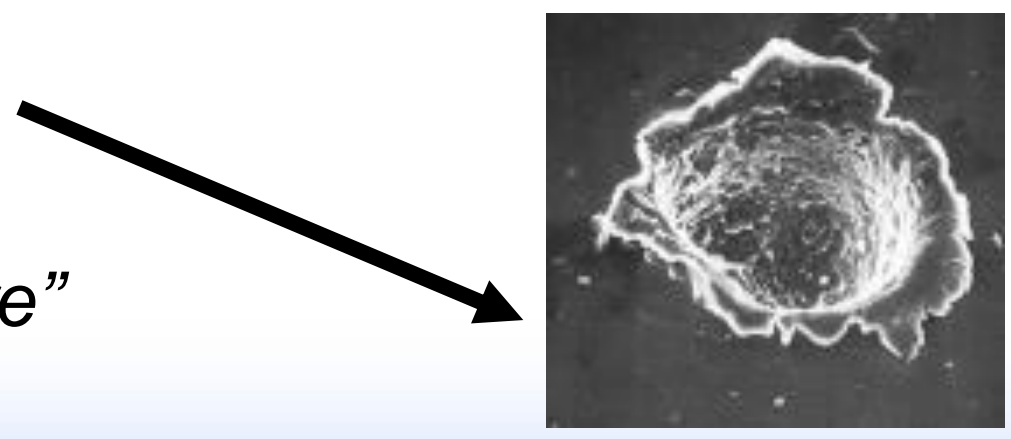

Shower of particles

below $(-2)$ of LH wing

after debris struck

wing

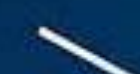




\section{Workshop - Value Tree}

- $\quad$ Value trees are hierarchical structures used to depict values held by decision makers

- They represent a model of values, goals, and objectives

- A value is something a person cares deeply about (e.g., minimize risk)

- A goal is a measure directed toward a specific outcome (e.g., nuclear power risk should be small)

- An objective is a level of attainment towards a goal (e.g. core damage frequency should be less than 1E-6/yr)

\section{Example Value Tree}

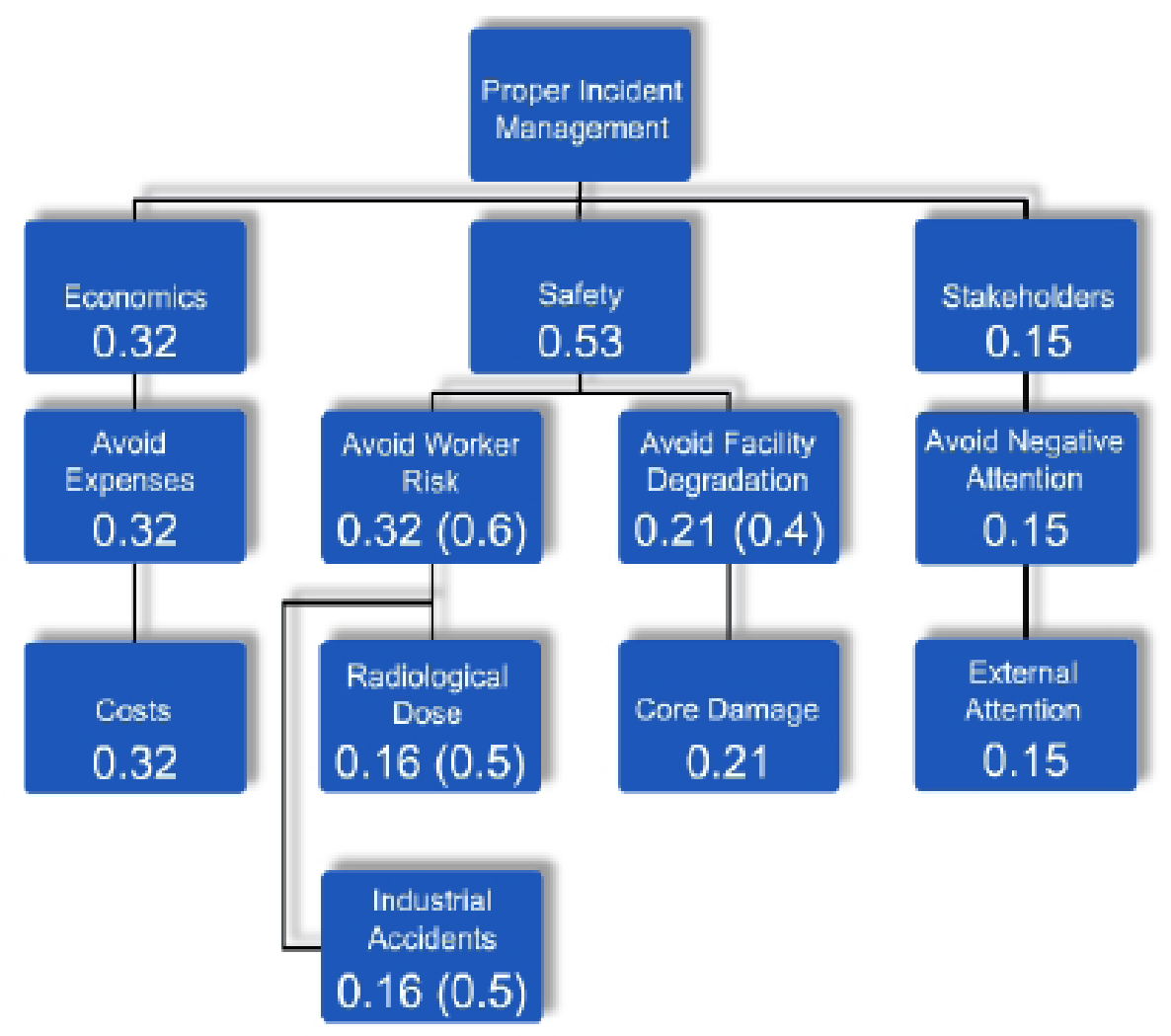

- Numerical values are weights

- For example, safety was deemed almost twice as important as economics 


\section{Workshop - Value Tree}

- Complete just the first level for your value tree aimed at "proper technical evaluation"

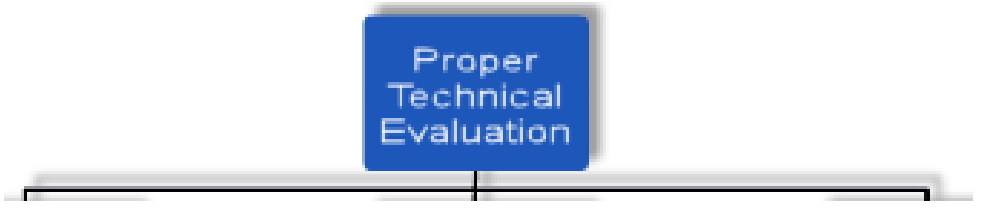

- Show potential items such as tractability, quality, ease (or not) of analysis, controversy (or not), cost, etc.

- Aim for a maximum of 5 or 6 primary values

- Try to assign weights (where the weights should sum to 1.0) 


\section{Uncertainty Identification}

- Tools and Techniques for identifying uncertainty

E.g., Separating "knowns" from
assumptions

- Questioning attitude required to identify uncertainties

- Comparisons between model predictions and "reality"

- Do the results make logical sense

- Quantitative methods

- Uncertainty propagation through a model

- Predictive models

- Critical thinking

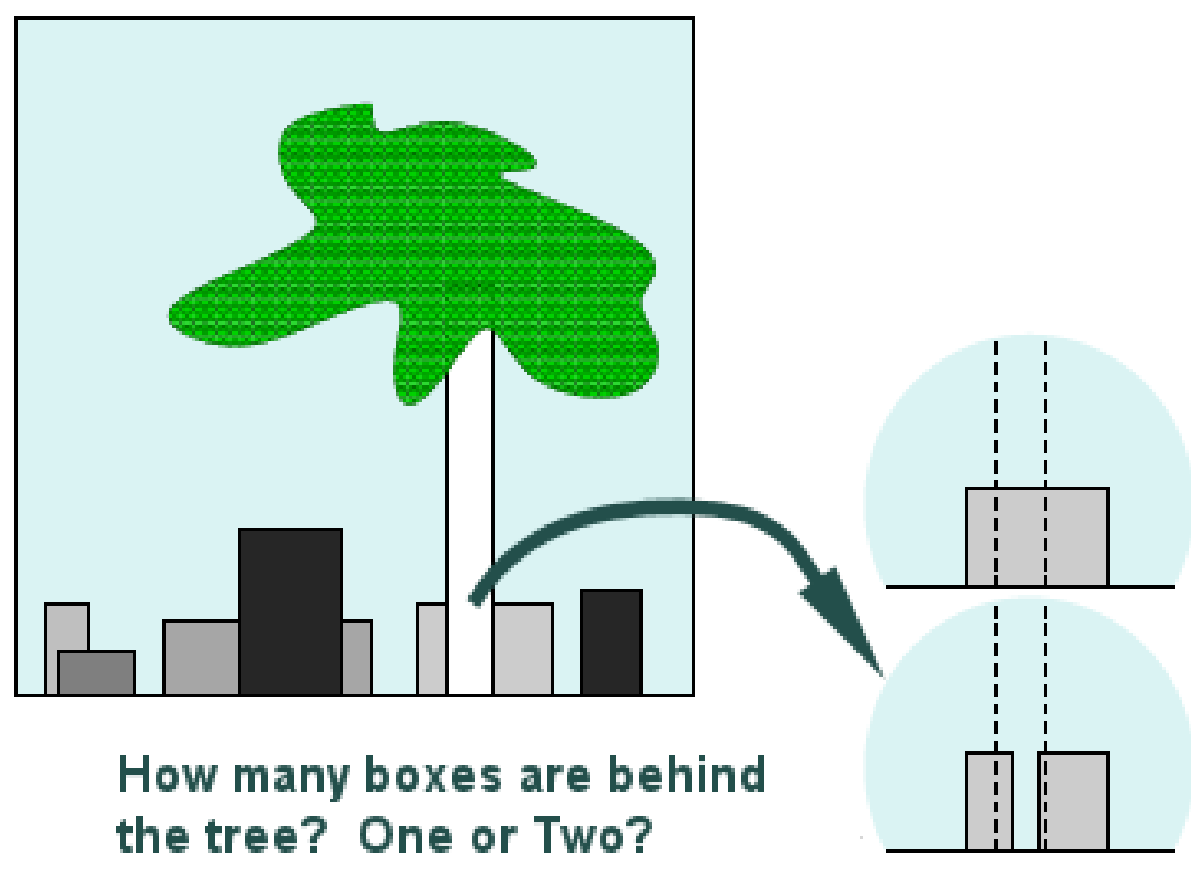

"Information Theory, Inference, and Learning Algorithms" D. MacKay 


\section{Uncertainty Identification}

- Critical thinking is important

- The process of thinking about an issue by which the quality of thought is improved

- Requires active control of the thought process

- Key elements to this process include

- Identifying and clearly describing questions and concerns

- Obtaining and evaluating relevant data and information

- Questioning internal assumptions and biases (Why? How do we know? Have we validated that?)

- Understanding possible implications of internalized information

- Expressing internalized information via written and verbal communications 


\section{Uncertainty Identification}

- Sparse data results in large uncertainties

- However, data alone might not be sufficient

- Data must be applicable to the problem at hand

- Issues that might "invalidate" available data

- Aging, environment, operating conditions

- Outside normal situation

- Simply not applicable

- Data must be interpreted correctly

- Failures and successes need to be critically evaluated

The analyst needs to question the basis for each step of this assessment to determine if it is sufficiently complete and accurate to produce a robust answer 


\section{Uncertainty Identification}

- Model uncertainties

- Is model appropriate for the problem

- Boundary conditions

- Is the system truly "as built"?

- Do we understand how it is operated, and is that modeled?

- Extrapolations/Interpolations

- Are the model relationships linear/nonlinear?

- Does the application require extending beyond modeling or observed bounds?

- Assumptions

- Identify key assumptions
- How do we define predictive accuracy for models?

- Need to think about observed versus unseen data

- We are interested in prediction of unseen data, rather than the data used to construct the model

- However, observed data and engineering knowledge...

- Indicates plausibility of model prediction for unseen data

- We are not $100 \%$ certain though since

- Observed data may not be representative

- Engineering knowledge may be flawed

What might be behind the tree...
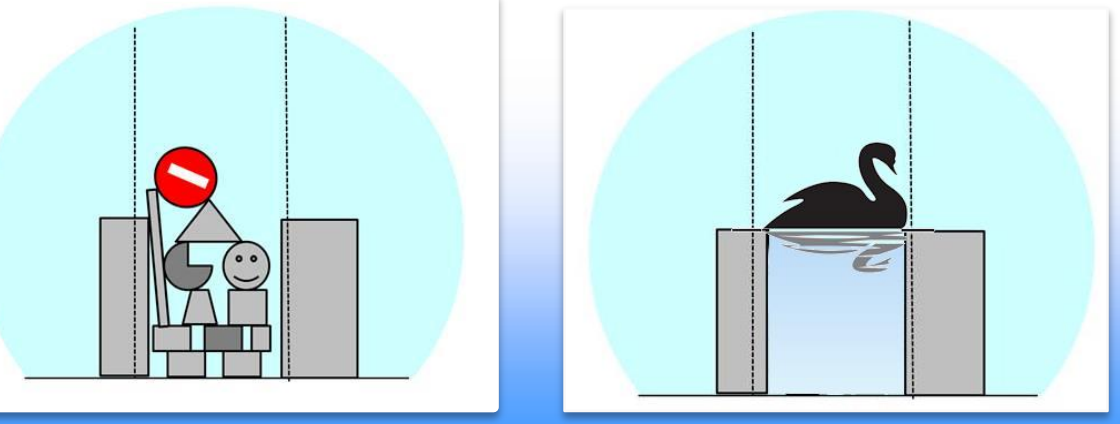


\section{Identifying the Uncertainties}

- What are some questions one might ask to identify significant uncertainties?

- Does current in-service inspection explicitly verify extent of degradation?

- Does laboratory or test data cover range of parameters/boundary conditions found in the plant?

- E.g., application extrapolated beyond bounds of tests

- Was expert elicitation used to compensate for lack of relevant data?

- Did experts previously predict that the observed phenomenon would not occur?

- Were the modeling assumptions only partially satisfied in practice?

- Is complex or poorly understood phenomena a part of the process?

Can you think of any other?? 


\section{Identifying the Uncertainties}

- Need to think "outside the box"

- For example, if I assume a flow accelerated corrosion model is not applicable

- I assign it a zero probability

- However, this is an extreme position to take

- Simply stating this probability does not make it true

- At the start, begin by questioning models and assumptions

- Discounting issues to start may lead to DM problems later

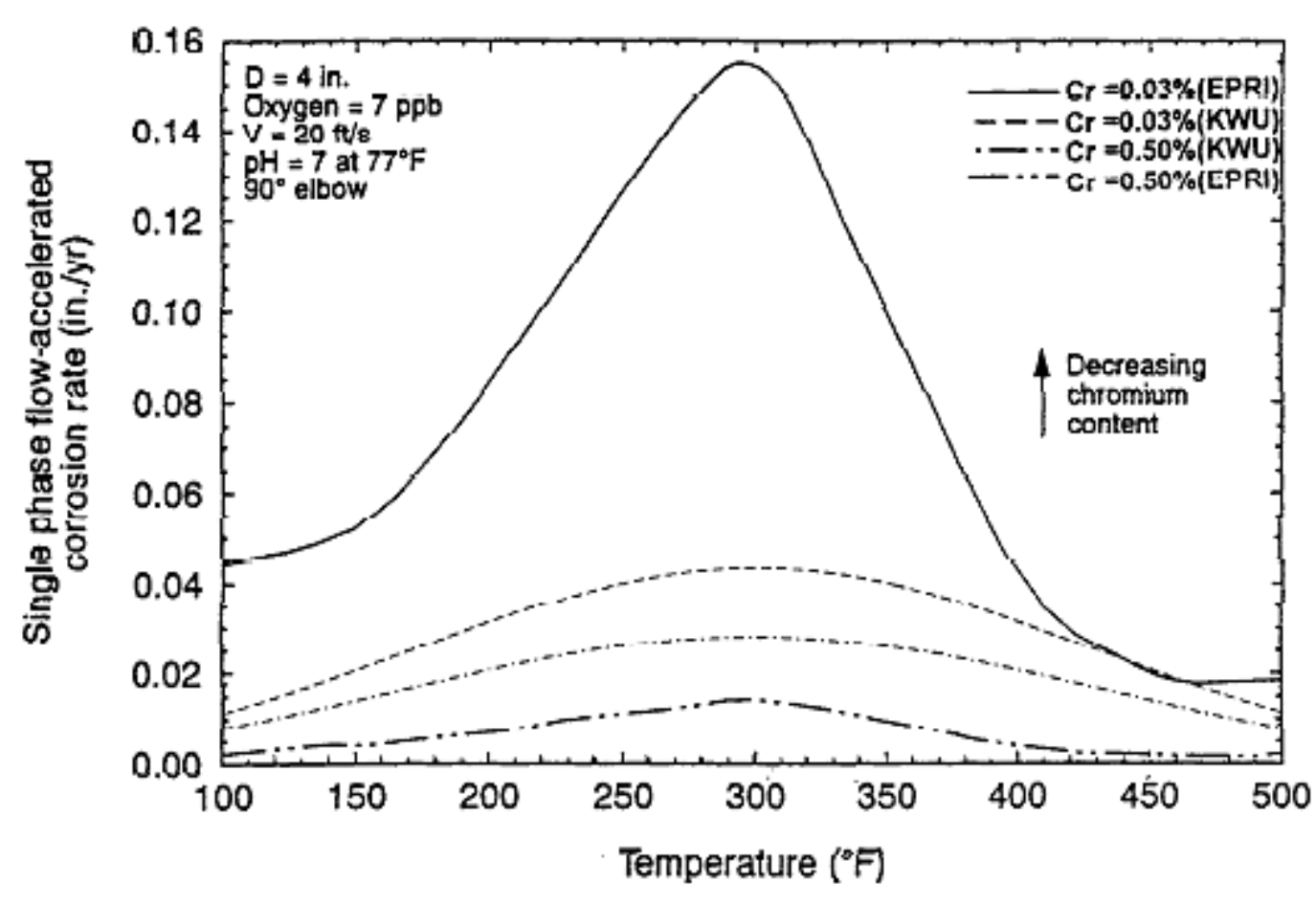




\section{Models are an Estimate of Reality}

- Observables such as pressure, temperature, wall thickness are estimated from models

- How well we make these predictions of degradation effects impacts the...

- Probabilities of failure. How well we predict probabilities of failure impacts...

- Risk (either on the likelihood or the consequences)

- These estimates affect our risk-informed decisions 


\section{Models are an Estimate of Reality}

- We need to be able to translate our knowledge of models into (ultimately) impacts on our decisions

Is our model providing adequate prediction of pump performance?

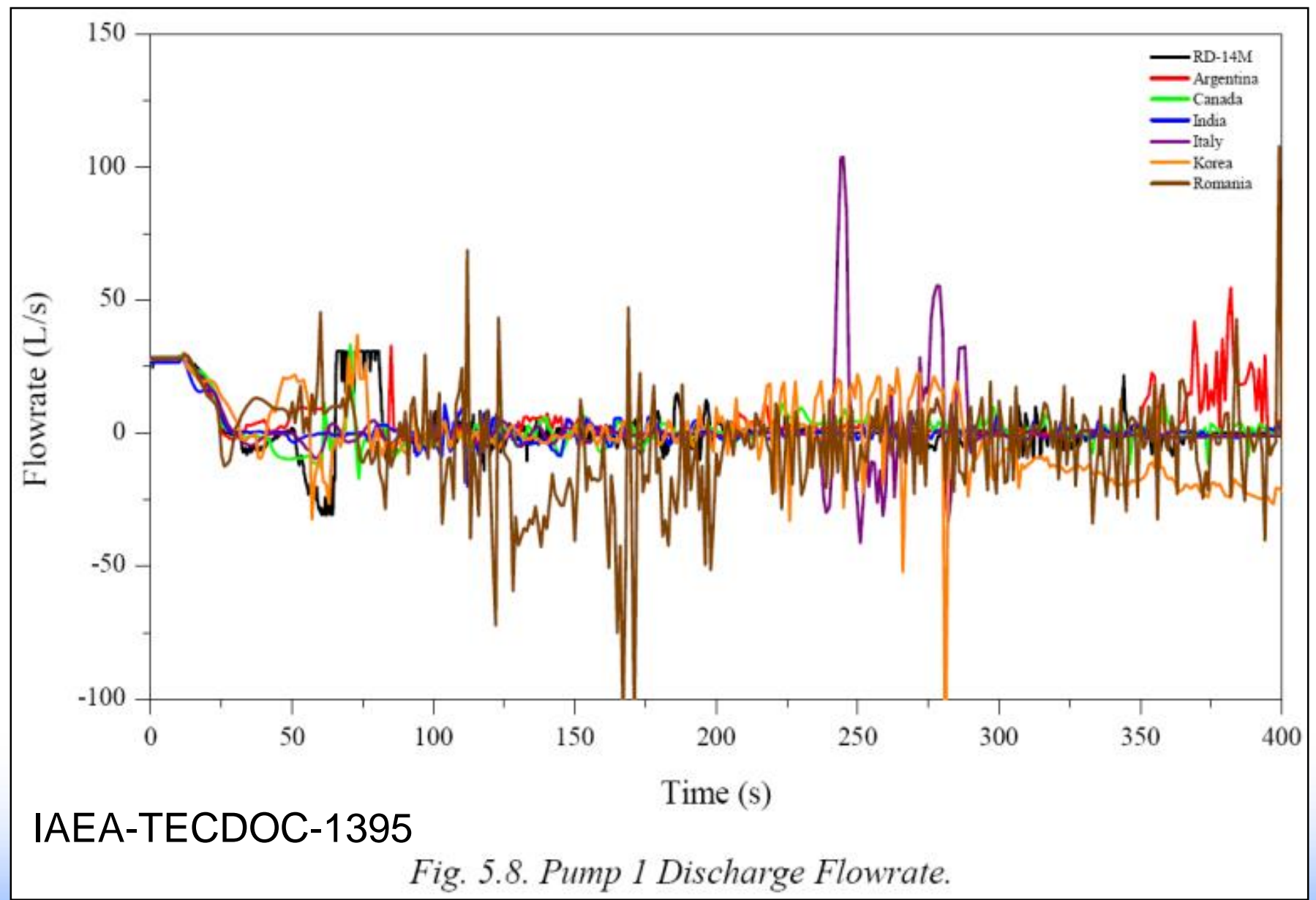




\section{Models are an Estimate of Reality}

- In order to connect our modeling approaches to our decision processes, we decompose models into two types

- Deterministic models \& Probabilistic models
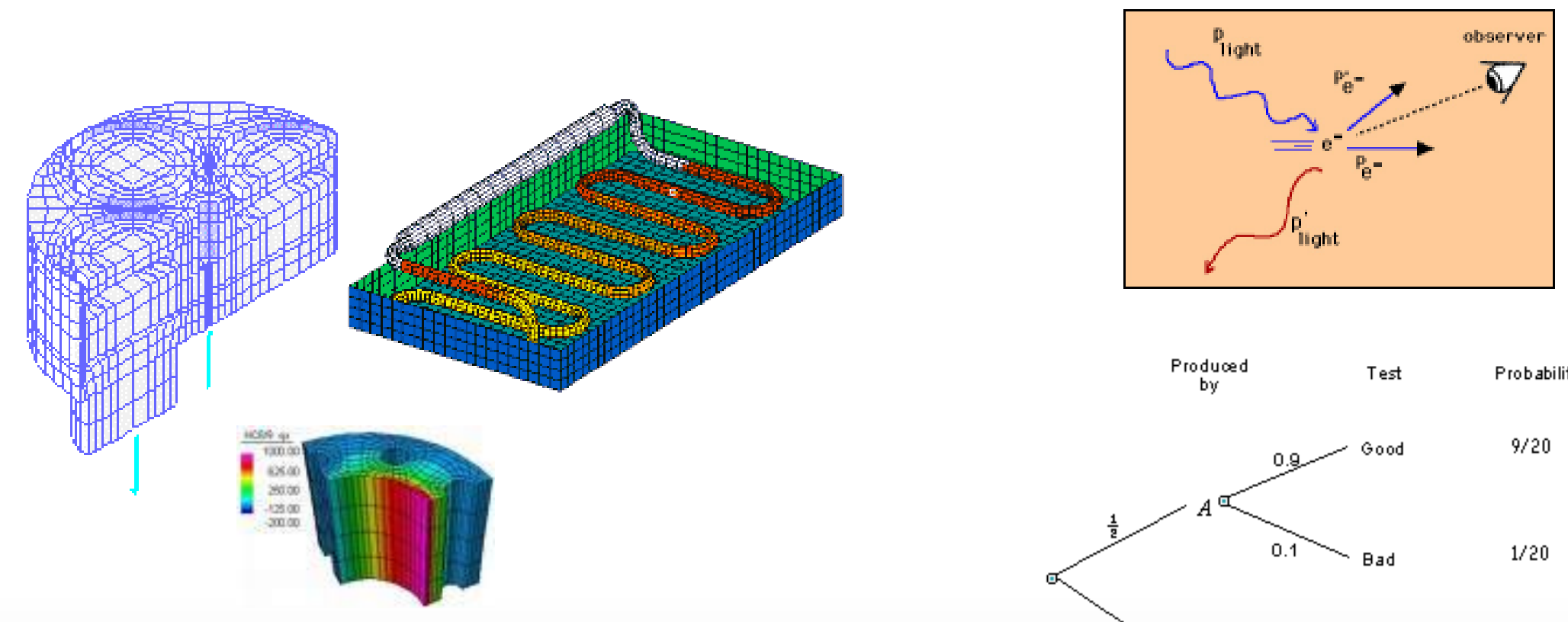

Produce

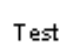

Probability

$9 / 20$

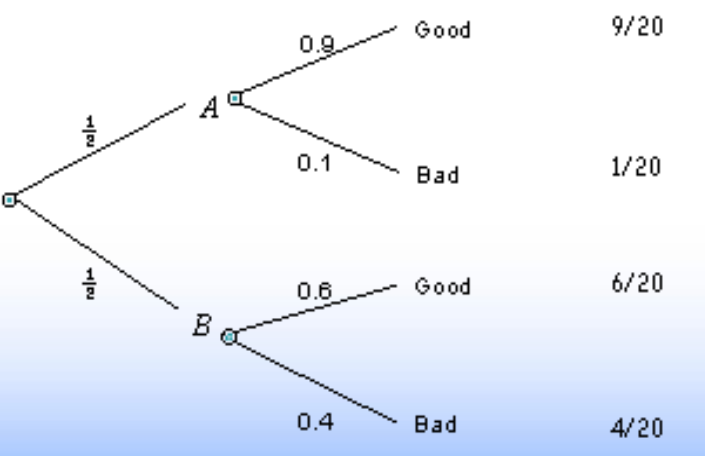

Idaho National Laboratory 


\section{Deterministic (or mechanistic) models}

- Different from probabilistic models

- This model represents situations where an observable quantity will be known given a certain set of parameter values

- For example, equation $E=m c^{2}$ is a deterministic model

- If we know mass $m$ and speed of light $c$ we know the energy $E$

- We may not know the energy precisely (we will know it up to our certainty in the model parameters)

- Other special model types have been offered by the scientific community

- A special type of deterministic model is chaotic systems

- Chaotic system behaves such that small changes to input yield behavior that appears to be stochastic

Definition of deterministic models:

Pertaining to phenomena-based events (e.g., material degradation), the outcome of which is known if the inputs are known with certainty 


\section{Deterministic models}

- How do we know that models such as $E=m c^{2}$ are correct? We test!

- From NIST (2005)

- By comparing measurements of energy emitted and measurements of mass of the same atoms, found that $E$ differs from $m c^{2}$ by at most 0.0000004 , or four-tenths of 1 part in 1 million

- This result is "consistent with equality"

- Unfortunately, such precision will never be available for our models

- Operating data and tests do help us validate our models though

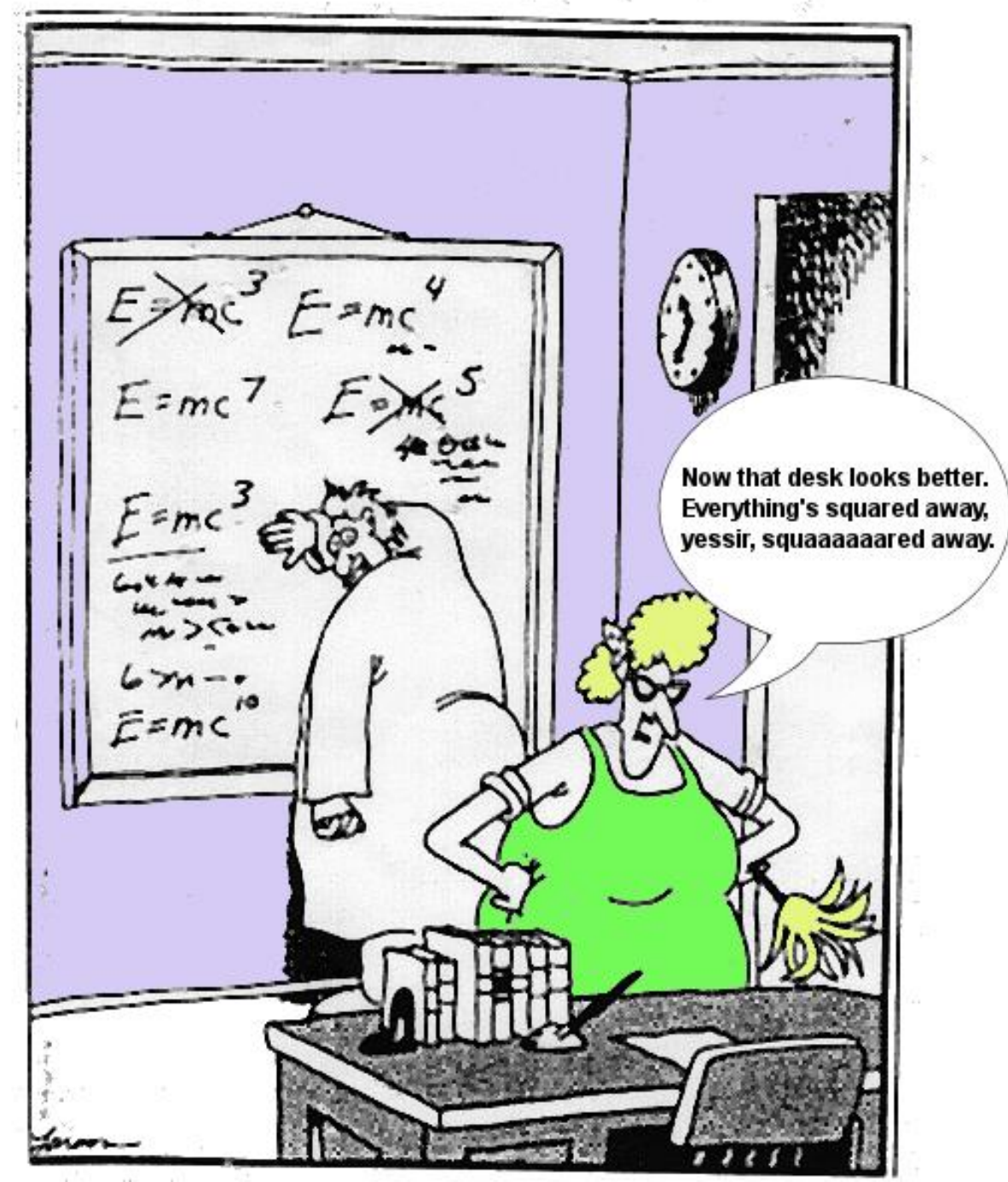

“The Far Side" Gary Larson 


\section{Probabilistic models}

- For probabilistic models, the outcome - while observable - is not certain

- We can speak of the probability of particular outcome

- For example, a pipe failure model may tell us the probability of seeing a single failure within the next year of plant operation

- A traditional example of a probabilistic model is that for radioactive decay

- We can not say when the next decay process will take place

- Can estimate the probability of a decay in a time interval

- If $T$ represents time of decay, then our estimate is

- $\operatorname{Pr}(T<t / \lambda$ and decay model $)=1-e^{-(\lambda t)}$

- Assumptions underlying decay model include

- Poisson process

- Constant rate of decay

- Parameter of the model-decay constant, $\lambda$

Definition of probabilistic models:

Pertaining to the probability prediction of experiencing an observable event (e.g., probability of a $0.1 \mathrm{gpm}$ leak given material degradation) 


\section{Deterministic \& Probabilistic}

- Interaction between these types of models leads to our "model of the world"

- Our model of the world, or simply model, is a mathematical equation, or set of equations, that gives predictions about an outcome of interest

- The outcome of interest is an observable quantity

- Note though that we can speak about the probability of seeing an outcome (even though probabilities are not observable)

- The model includes both assumptions and parameters

- Both of which may be uncertain

- However, the model output is conditional upon those assumptions and parameters

"All models are wrong, but some are useful." - George Box 


\section{COLUMBIA}

Idaho National Laboratory 


\section{Results of Retrospective Analysis on Shuttle Risk}

Source: Shuttle Risk Progression: Use of the Shuttle Probabilistic Risk Assessment (PRA) to Show Reliability Growth, Teri L Hamlin et al. (AIAA, 2010) (downloadable from http://ntrs.nasa.gov/archive/nasa/casi.ntrs.nasa.gov/20110004917_2011004008.pdf)

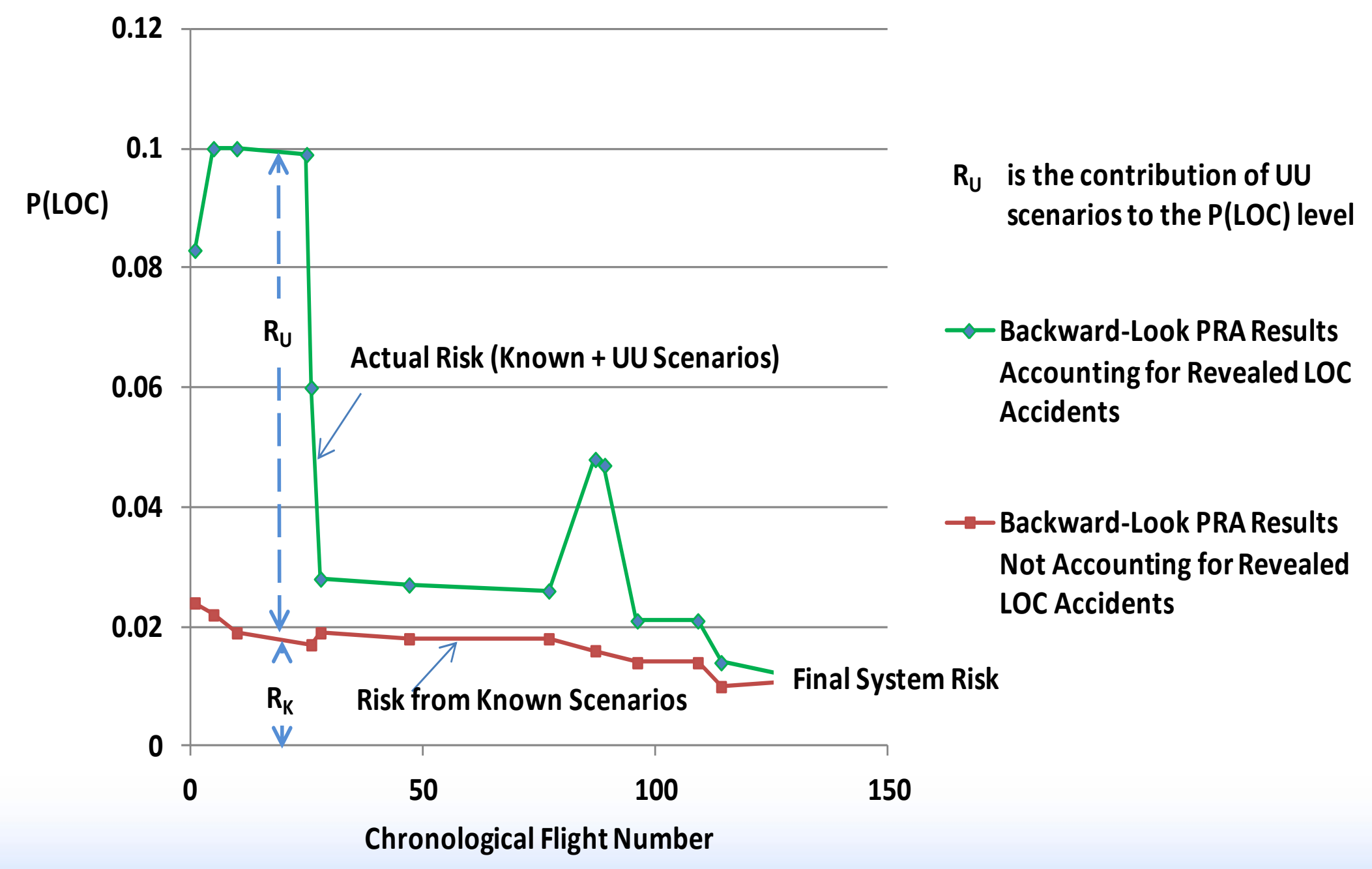


An Accident Precursor Analysis Technical Approach for NASA Space Systems and Pilot Program Application, Draft Final Report, May 2008

\section{Precursors to Columbia Accident}

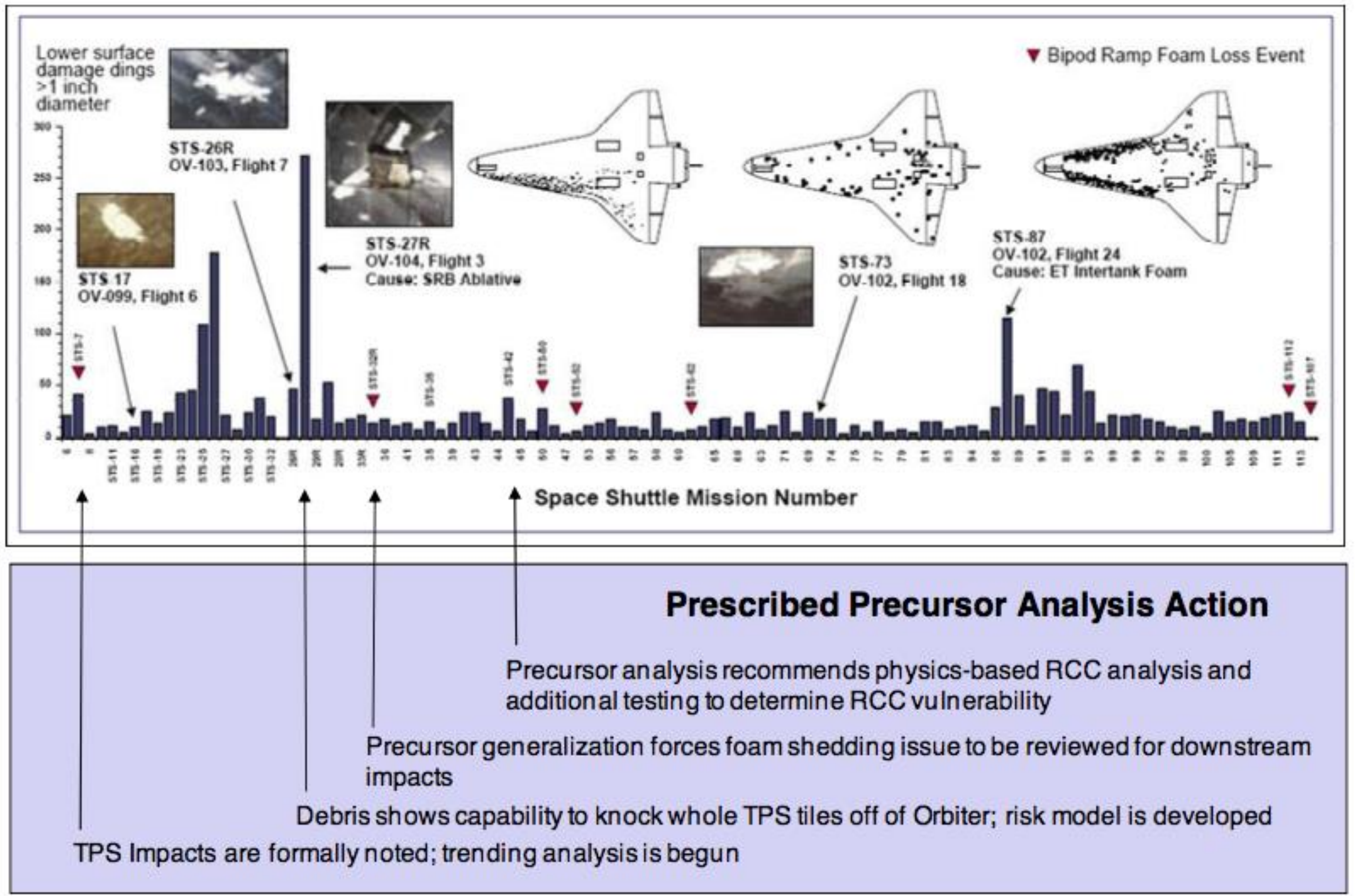

Figure 13. Space Shuttle Debris Damage Timeline and Prescribed APA Response 


\section{THE CRATER MODEL}

$p=\left[0.0195(L / d) 0.45(d)\left(\rho_{P}\right)^{0.27}\left(V-V^{*}\right)^{2 / 3}\right] /\left[\left(S_{T}\right)^{1 / 4}\left(\rho_{T}\right)^{1 / 6}\right]$

$p=$ penetration depth

$L=$ length of foam projectile

$d=$ diameter of foam projectile

$\rho_{P}=$ density of foam

$V=$ component of foam velocity at right angle to foam

$V^{*}=$ velocity required to break through the tile coating

$S_{T}=$ compressive strength of tile

$\rho_{T}=$ density of tile

0.0195 = empirical constant

- In 1966, during the Apollo program, engineers developed an equation to assess impact damage, or "cratering," by micrometeoroids. 44 The equation was modified between 1979 and 1985 to enable the analysis of impacts to "acreage" tiles that cover the lower surface of the Orbiter.45 The modified equation, now known as Crater, predicts possible damage from sources such as foam, ice, and launch site debris, and is most often used in the day-of-launch analysis of ice debris falling off the External Tank.46 


\section{THE CRATER MODEL}

- When used within its validated limits, Crater provides conservative predictions (that is, Crater predictions are larger than actual damage). When used outside its validated limits, Crater's precision is unknown.

\begin{tabular}{|l|l|l|}
\hline Test Parameter & Test Value & STS-107 Analysis \\
\hline Volume & Up to 3 cu.in & $\begin{array}{l}10^{\prime \prime} \times 6^{\prime \prime} \times 20^{\prime \prime}=1200 \\
\text { cu.in. }{ }^{*}\end{array}$ \\
\hline Length & Up to 1 inch & $\sim 20$ inches * \\
\hline Cylinder Dimensions & $<=3 / 8^{\prime \prime}$ dia $\times 3^{\prime \prime}$ & $6^{\prime \prime}$ dia $\times 20^{\prime \prime}$ \\
\hline $\begin{array}{l}\text { Projectile Block } \\
\text { Dimensions }\end{array}$ & $<=3^{\prime \prime} \times 1^{\prime \prime} \times 1^{\prime \prime}$ & $6^{\prime \prime} \times 10^{\prime \prime} \times 20^{\prime \prime}{ }^{*}$ \\
\hline Tile Material & Ll-900 "acreage" tile & Ll-2200 * and LI-900 \\
\hline Projectile Shape & Cylinder & Block \\
\hline
\end{tabular}

* Outside experimental test limits 
Which of the previously-mentioned decision-making or modeling faults occurred in the handling of the Columbia event?

- Previously Mentioned:

- Anchoring

- Status quo

- Sunk costs

- Confirming evidence

- Estimating and forecasting

- Incompleteness

- Hypothesis space

- Model

- Normalization of Deviance 


\section{FUKUSHIMA}




\section{Tsunami representation}

Have seen one large

$(\sim 15 \mathrm{~m})$ event in $\sim 200$

years of reactor

operation in Japan

Source: Tadashi Annaka, Kenji Satake, Tsutomu

Sakakiyama, Ken Yanagisawa, Nobuo Shuto, Logic-tree Approach for Probabilistic Tsunami Hazard Analysis and its Applications to the Japanese Coasts, Pure appl. geophys. 164 (2007) 577-592

http://link.springer.com/chapter/10.1007\%2F978-3-76438364-0_17\#page-1

(c) $10^{0}$

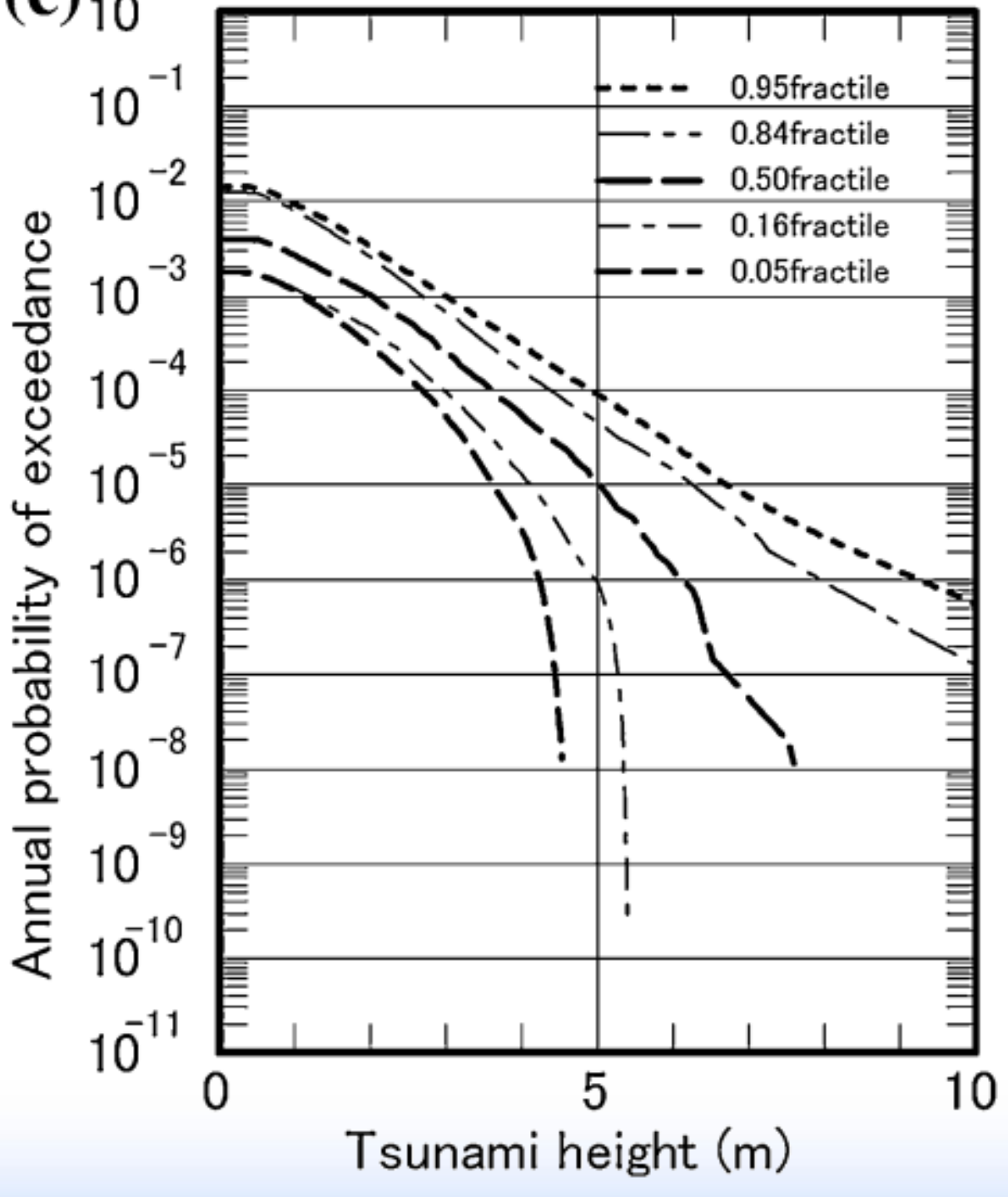


Which of the previously-mentioned decision-making or modeling faults occurred in the handling of the Fukushima event?

- Previously Mentioned:

- Anchoring

- Status quo

- Sunk costs

- Confirming evidence

- Estimating and forecasting

- Incompleteness

- Hypothesis space

- Model

- Normalization of Deviance 


\section{Integrated Decision Making}

- Even though results are uncertain, we can use them to help make decisions (risk informed decision making)

- Formal decision process embraces the concept of uncertainty

- Nobel prizes have been awarded from this "embrace"

- For example, the stochastic economic model (Black-Scholes formula) awarded Nobel in 1997

- Every real decision takes place under uncertainty

- Ignoring this uncertainty does not make it go away

- "PowerPoint engineering" typically has a myopic view of the world

- Need to think critically about the processes one is modeling 


\section{Final Thoughts}

Course Objective: Improve NRC staff's awareness of the factors that contribute to uncertainty in predictive models and the need to identify, characterize and communicate the uncertainties to the risk-informed decision-maker

- $\quad$ "Remember that all models are wrong; the practical question is how wrong do they have to be to not be useful"

- George Box

- To evaluate "wrongness" we need to THINK

- This is not easy

- There is no procedure

- Need to support the decision-making process

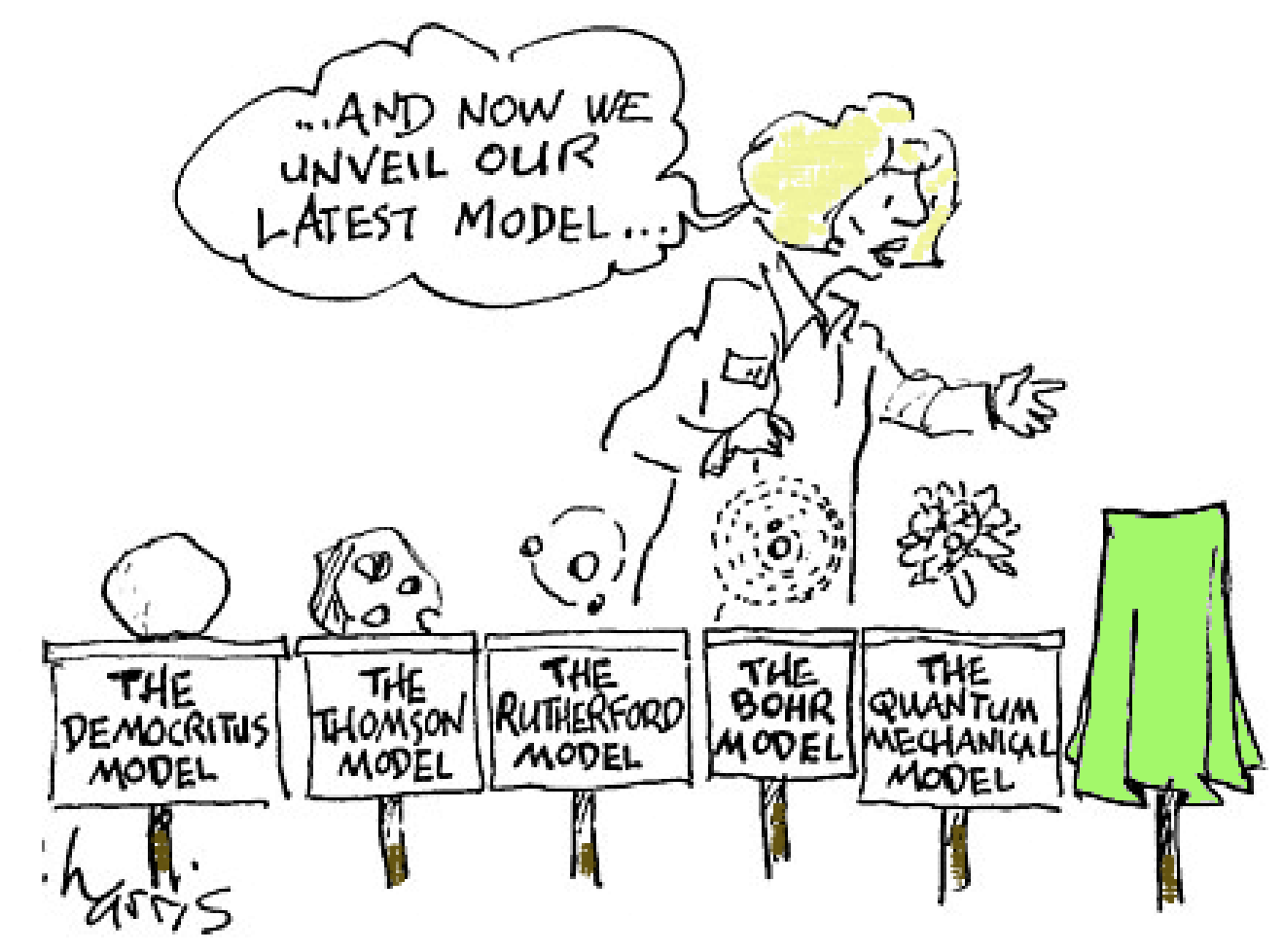

Sidney Harris 


\section{Final Thoughts}

- Determining model adequacy is not a trivial process

- Army Corps of Engineers

- "...significant part of complexity in describing the uncertainty associated with model projections is due to the large number of variables, parameters, and performance"

- "Even if more sophisticated methods were used for model calibration and uncertainty analysis... many factors are hard to quantify"

- "Given that an accurate assessment of the complete uncertainty underlying such models is unlikely, the use of these models for decision making should be accompanied by appropriate caveats and disclaimers..." 


\section{Final Thoughts}

- E. T. Jaynes, Probability Theory - The Logic of Science, 2003

"In other applications of mathematics, if we fail to use all of the relevant data of a problem, the result will not be that we get an incorrect answer. The result will be that we are unable to get any answer at all.

But probability theory cannot have any such built-in safety device, because, in principle, the theory must be able to operate no matter what our incomplete information might be. If we fail to include all of the relevant data, or to take into account all the possibilities allowed ...probability theory will still give us a definite answer...but that answer may be in violent contradiction to our common sense judgments which did take everything into account, if only crudely.

The onus is always on the user to make sure that all the information ... is actually incorporated ....and that the full extent of his ignorance is also properly represented." 


\section{Final Thoughts}

- John Sterman (in "All models are wrong: reflections on becoming a systems scientist") describing "Invisible fences in the mind"

"In affluent suburbs of the United States many dog owners now use invisible fences...you bury a cable around the perimeter of your yard... After a short training period, you can turn off the collar. The dog will still not cross the invisible fence.

We are just the same. We live in a society that trains us to stay within artificial and damaging boundaries far more effectively than any invisible fence trains a dog. Much of our education consists of getting punished for crossing boundaries...

These invisible lines in the mind are the boundaries of our mental models." 


\section{Final Thoughts}

- From Mark Kirk [NUREG-1806 (PTS) project manager]

"[at] the time of project inception, when us materials folks learned that we needed to 'address uncertainties' many of us thought that all that was needed was to construct uncertainty distributions on our input variables (copper, nickel, fracture toughness, etc.) and provide these to the programmers developing the PFM code."

"What we learned is that it is fundamentally impossible to talk about how uncertainties are represented in a calculation outside of the context provided by the overall model that links all of the parameters and sub-models together."

"So when we started we really got the cart before the horse ... we needed to focus first on building the overall model, not on figuring out the standard deviation on copper (for example)."

"If I were to take one lesson away from PTS it is this: before you understand the total model [analysis process] that gets you from all of your inputs to your calculated end result you have no business talking about uncertainties." 


\section{References}




\section{References}

- Army Corps of Engineers, "Model Uncertainty Workshop Report," July 2002

- NUREG-CR-5632, "Incorporating Aging Effects into PRA - Feasibility study utilizing reliability physics models," 2001.

- NUREG-1806, "Technical Basis for Revision of the Pressurized Thermal Shock (PTS) Screening Limit in the PTS Rule (10 CFR 50.61): Summary Report."

- RG 1.174, "An Approach for Using Probabilistic Risk Assessment in Risk-Informed Decisions on PlantSpecific Changes to the Licensing Basis." 


\section{References}

- RG 1.200, "An Approach for Determining the Technical Adequacy of Probabilistic Risk Assessment Results for Risk-Informed Activities.

- NUREG/CR-6840, "The Technical Basis for the NRC's Guidelines for External Risk Communication."

- John Sterman, "All models are wrong: reflections on becoming a systems scientist" (2002) System Dynamics Review 18(4): 501-531.

- Edward T. Jaynes, "Probability Theory - The Logic of Science," 2003.

- David MacKay, "Information Theory, Inference, and Learning Algorithms," 2003. 